\title{
2,2'-Dipyridylamines: More Than Just Sister Members of the Bipyridine Family. Applications and Achievements in Homogeneous Catalysis and Photoluminescent Materials
}

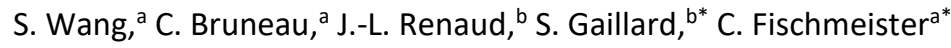 \\ aUniv Rennes. UMR CNRS 6226, Institut des Sciences Chimiques de Rennes \\ Université de Rennes 1. 263, avenue du général Leclerc, 35000 Rennes (France) \\ E-mail: cedric.fischmeister@univ-rennes1.fr; christian.bruneau@univ-rennes1.fr \\ ${ }^{b}$ Normandie Univ., LCMT, ENSICAEN, UNICAEN, CNRS, \\ 6 boulevard du Maréchal Juin, 14000 Caen (France) \\ E-mail : sylvain.gaillard@ensicaen.fr
}

\begin{abstract}
2,2'-Dipyridylamine (dpa) and related compounds belong to the family of polydentate nitrogen ligands. More than a century has passed since its first report but new complexes and applications have been emerging in the recent years owing to the versatility of dpa-based architectures. This review aims to present and highlight the main achievements attained with dpa-containing metal complexes in the domains of homogeneous catalysis and luminescent materials.
\end{abstract}

\section{Introduction}

Chelating ligands play a pivotal role in coordination and organometallic chemistry with multiple applications in various domains. Beyond the ubiquitous bis-pyridine, ${ }^{1}$ bis-imine and related ligands, ${ }^{2}$ bisoxazoline ${ }^{3}$ and $\mathrm{NacNac}^{4}$ ligands ( $\beta$-diketiminate), 2,2'-dipyridylamine (dpa)-based ligands have been much less explored. If the first report of dpa synthesis using sodium amide goes back to $1914,{ }^{5}$ it is only in the second half of the $20^{\text {th }}$ century that this class of compounds was more actively investigated, in particular in coordination chemistry owing to the multiple coordination mode they allow. ${ }^{6}$ Surprisingly, despite the rapid growth of $N^{\prime} N$-chelating ligands in catalysis and material sciences, it is only recently that dpa ligands have attracted increasing interest in these domains. The facilitated synthesis of dpaderivatives through Pd-catalysed amination reactions ${ }^{7}$ and the modularity of this ligand undoubtedly contributed to their increasing interest (Figure 1). The present review aims to present the recent developments and applications of organometallic complexes incorporating dipyridylamine ligands L1 in catalysis and material sciences with an emphasis on luminescent materials. When possible, complexes coordinated to the well-known bipyridine, bpy-L2, or 1,10-phenantroline, phen-L3, ligands will be compared to highlight the differences between these two classes of ligands (Figure 1).

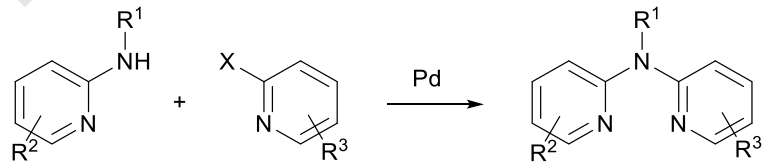

$\mathrm{R}^{1}$ : steric \& electronic effects, anchorage site for supported catalysis $R^{2}, R^{3}$ : steric \& electronic effects, stereo-induction dipyridylamine (dpa) $L 1: R^{1}=R^{2}=R^{3}=H$

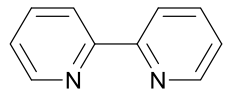

bpy L2

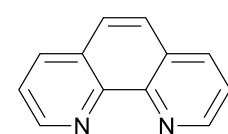

phen L3

Figure 1 Dipyridylamine-based ligands by Pd-catalysed amination 


\section{Homogeneous Catalysis}

\subsection{Reduction reactions}

Reduction and oxidation reactions are major transformations in organic chemistry and industrial processes. Recently, these reactions have seen renewed interest with the growing development of sustainable resources and energies. ${ }^{8}$

In 1999, the electroreductive coupling of aromatic halides was reported in ethanol using a catalyst in situ generated from $\mathrm{NiBr}_{2}, 3 \mathrm{H}_{2} \mathrm{O}$ and dpa $\mathbf{L} 1{ }^{9}{ }^{9} \mathrm{~A}$ number of biaryl compounds were obtained in yields higher than those obtained when the catalyst was prepared with 2,2'-bipyridine (bpy) $\mathbf{L} 2$ as ligand. In particular, several compounds not accessible with $\mathrm{NiBr}_{2}(\mathbf{L} \mathbf{2})$ were synthesized in modest to good yields with $\mathrm{NiBr}_{2}(\mathbf{L 1})$ (Scheme 1, a). Similarly, the same catalyst was utilized for the conjugate addition of arylbromides on activated olefins in ethanol (Scheme 1, b).

(a)

2

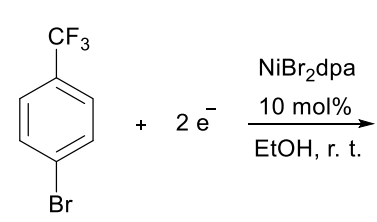<smiles>FC(F)(F)c1ccc(-c2ccc(C(F)(F)F)cc2)cc1</smiles>

(b)

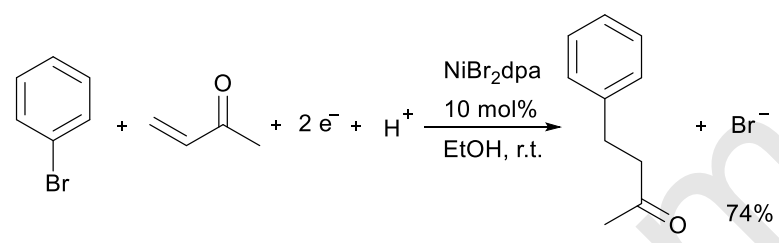

Scheme 1 Nickel-catalysed electrosyntheses

Another example of electrocatalytic reduction was reported in 2009 by Wong. ${ }^{10} \mathrm{~A}$ pyrrole-tagged dpa ligand $\mathbf{L} \mathbf{4}$ was reacted with a rhenium precursor leading to the $\operatorname{Re}(\mathrm{I})$ complex $\mathbf{C} \mathbf{1}$ shown in Figure 2 . This monomer was easily electropolymerized onto a glassy carbon electrode in acetonitrile. This electrode was found active for the electroreduction of $\mathrm{CO}_{2}$ to $\mathrm{CO}$ as demonstrated by cyclic voltammetry measurements performed under an argon atmosphere and under a $\mathrm{CO}_{2}$ atmosphere.
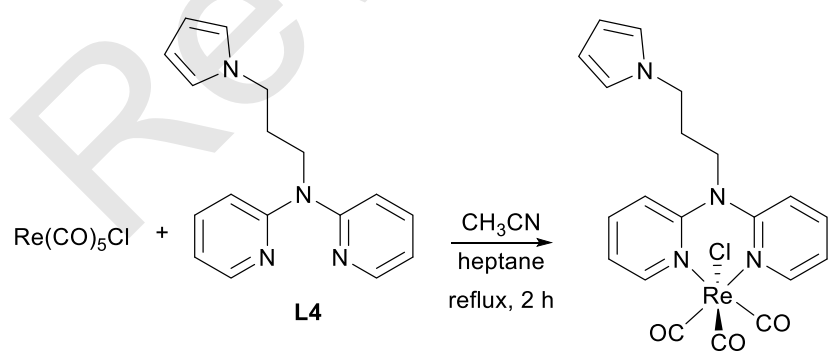

C1, $77 \%$

Figure 2 Pyrrole-tagged rhenium complex C1. 
More recently, the electrochemical reduction of $\mathrm{CO}_{2}$ was investigated with metal carbonyl complexes of tungsten and molybdenum bearing bipyridine and dpa ligands (Figure 3). ${ }^{11}$ Interestingly, catalyst C2 outperformed the bpy-based catalysts $\mathbf{C} 3$ in preparative scale reduction of $\mathrm{CO}_{2}$ into $\mathrm{CO}$. Mechanistic investigation also revealed a major difference between the bpy- and dpa-based catalysts. Indeed, contrary to bpy-ligand, experimental and theoretical results suggested a non-innocent behaviour of the dpa ligand with CO formation mainly localized on the dpa-ligand rather than on the metal centre.<smiles>O=[N+]([O-])[N+]1NCCCN1</smiles>

C2: $\mathrm{N} N=L 1$

C3: $\mathrm{N}=\mathrm{N}=\mathrm{N}$<smiles>c1ccc(Nc2ccccn2)nc1</smiles>

L1

Figure 3 Catalyst for electroreduction of $\mathrm{CO}_{2}$ into $\mathrm{CO}$

The imidazolium-tagged dpa ligand $\mathbf{L} \mathbf{6}$ was easily prepared and used as stabiliser of Pd nanoparticles for hydrogenation of olefins under biphasic conditions (Figure 4). ${ }^{12}$

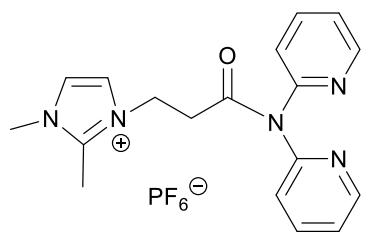

$\left[\mathrm{BMMDPA}^{\mathrm{s}}\left[\mathrm{PF}_{6}\right] \mathbf{L 6}\right.$

Figure 4 Water-soluble dpa-based ligand

The Pd nanoparticles were easily in situ prepared by mixing $\mathrm{Pd}(\mathrm{OAc})_{2}$, the tagged-dpa ligand $\mathbf{L} 6$ and an ionic liquid in acetone followed by reduction of $\mathrm{Pd}(\mathrm{II})$ with dihydrogen. This catalyst could perform quantitatively the hydrogenation of cyclohexene, styrene and ethyl acrylate at $35^{\circ} \mathrm{C}$ under 1 bar of dihydrogen pressure. After separation, the catalyst was reused two times without yield lessening. Water compatibility is also accessible using ionic complexes. In 2010, a series of cationic ruthenium complexes were prepared and implemented in the aqueous phase transfer hydrogenation of ketones (Figure 5). ${ }^{13}$

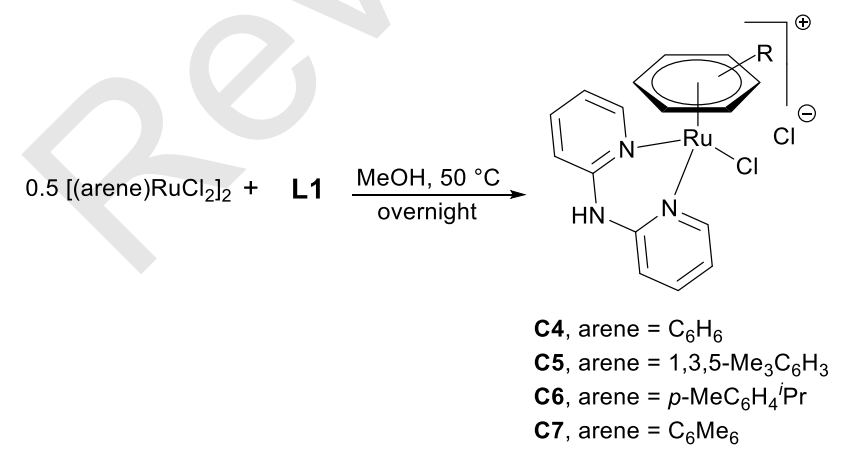

Figure 5 Cationic ruthenium-dpa complexes 
Several ketones were efficiently reduced at $65^{\circ} \mathrm{C}$ in water with $\mathrm{C6}$ and $\mathrm{HCO}_{2} \mathrm{H} / \mathrm{HCOONa}$ (Figure 6). The recyclability of the catalyst was investigated showing a rapid decrease of conversion after the second run.

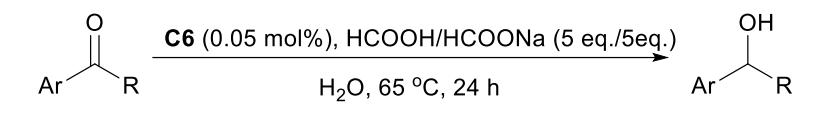<smiles>CCC(O)c1ccc(C)cc1</smiles>

$86 \%$<smiles>OC(CBr)c1ccccc1</smiles>

$99 \%$<smiles>COc1ccc(C(C)O)cc1</smiles>

$99 \%$<smiles>CC(O)c1ccc(Br)cc1</smiles><smiles>COc1ccccc1C(C)O</smiles>

$99 \%$<smiles>CC(O)c1ccc2ccccc2c1</smiles>

Figure 6 Aqueous phase transfer hydrogenation of ketones

Simultaneously, Pandey and coworkers reported the synthesis and characterization of a series of cationic Ru-dpa complexes with various coordination spheres consisting of 2,2'-dipyridylamine L1 or di2-pyridylbenzylamine (dpb) $\mathbf{L} 7, p$-cymene and benzene as arene, $\mathrm{Cl}, \mathrm{N}_{3}, \mathrm{CN}, \mathrm{SCN}$ as $\mathrm{X}$ ligand and $\mathrm{PF}_{6}$ or $\mathrm{BF}_{4}$ as counter-ion (Figure 7). ${ }^{14}$ The chloro-complexes were evaluated in the transfer hydrogenation of acetophenone and benzophenone at $82^{\circ} \mathrm{C}$ using isopropanol as hydrogen source. As generally observed with ruthenium complexes in catalysis, the $\eta^{6}$ - $p$-cymene complex displayed better performances than the $\eta^{6}$-benzene derivative.

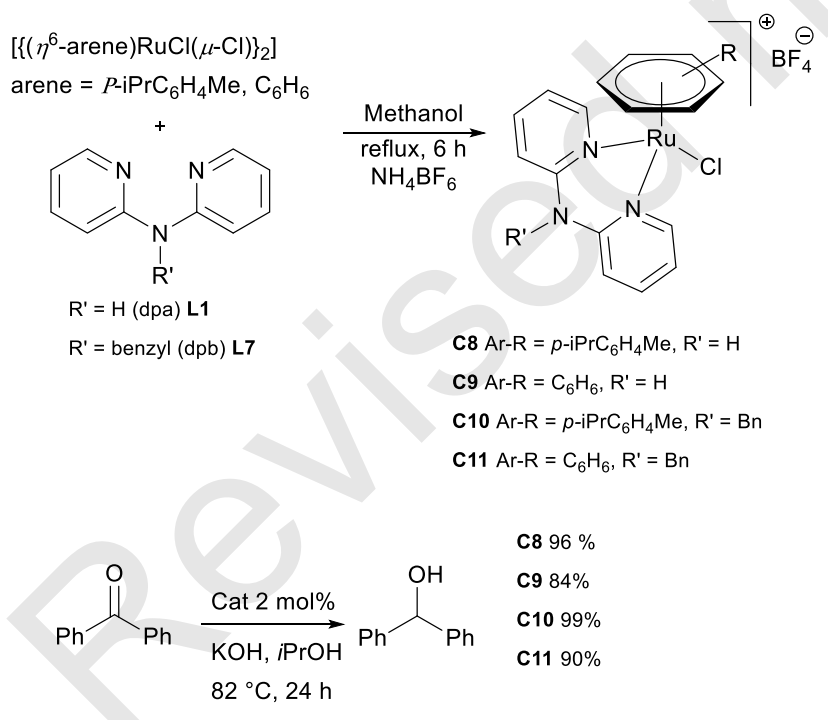

Figure 7 Transfer hydrogenation of ketones

The group of Salmain reported a series of studies in bioinorganic chemistry involving organometallic complexes incorporating dpa ligands. The structural modularity of the ligand was first used for the synthesis of ruthenium complexes C12-C14 bearing a thiol-reactive maleimide function aimed at inactivating the cysteine endoproteinase papain by $S$-alkylation of the cysteine active site (Figure 8$){ }^{15}$ These complexes and related rhodium complexes were later evaluated in the catalytic reduction of NAD ${ }^{+}$ 
into $\mathrm{NADH} .{ }^{16}$ The results demonstrated the great superiority of Rh vs $\mathrm{Ru}$ and revealed that catalysts bearing the $\mathrm{N}$-alkylated dpa ligands were not as efficient as bispyridine or phenanthroline-derived complexes of different structures.
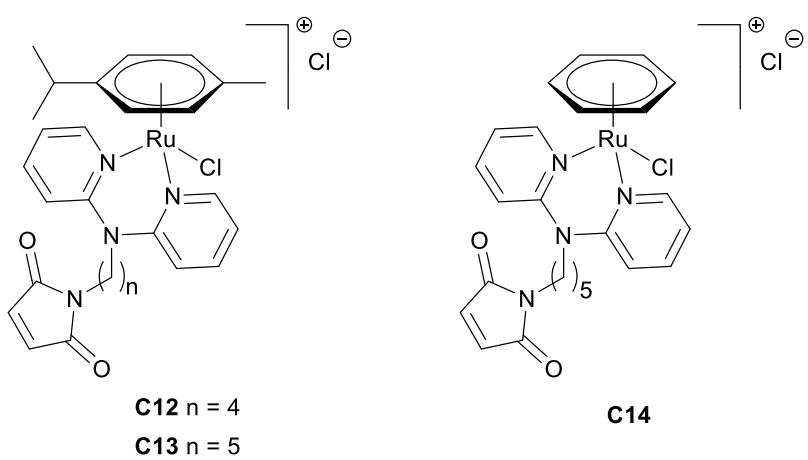

Figure 8 Complexes used in the reduction of $\mathrm{NAD}^{+}$using sodium formate as hydride source

The modularity of the dpa ligand was further extended to the synthesis of artificial metalloenzymes derived from bovine $\beta$-lactoglobulin. ${ }^{17}$ A series of complexes bearing a dpa ligand $N$-alkylated with saturated and unsaturated fatty acids was prepared and characterized (Figure 9). These complexes were initially evaluated in the transfer hydrogenation of trifluoroacetophenone (TFACP) where rhodium catalysts yet surpassed their ruthenium analogs. The supramolecular assembling of these complexes within $\beta$-lactoglobulin was realised in $\mathrm{EtOH}$ or DMSO at $\mathrm{pH} 7.5$ and the association was evidenced by circular dichroism and fluorescence spectroscopy. The resulting supramolecular catalysts were evaluated in the asymmetric transfer hydrogenation of trifluoroacetophenone with formate. Most complexes retained their original activity but the enantiomeric excess reached a low maximum value of $32 \%$ for the $(R)$-enantiomer.

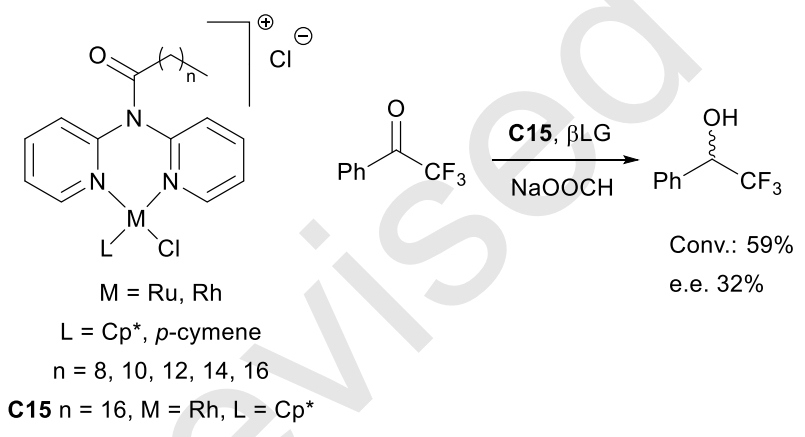

Figure 9 Artificial metalloenzyme for the asymmetric transfer hydrogenation of TFACP

The potential of dpa ligands in transition metal-catalyzed reduction was extended to the valorization of bio-sourced compounds such as levulinic acid. A series of dpa-based ruthenium and iridium complexes was evaluated in the transfer hydrogenation and hydrogenation of levulinic acid (Figure 10). ${ }^{18}$ In the M$\mathrm{Cl}$ series, transfer hydrogenation was performed under neat conditions in the presence of triethylamine. Both ruthenium and iridium complexes were shown competent for this transformation but iridium catalysts, in particular C19, were slightly more efficient as they could perform the reduction of levulinic acid at $120^{\circ} \mathrm{C}$ when a temperature of $150^{\circ} \mathrm{C}$ was necessary with the most efficient ruthenium catalyst C18. Nevertheless, recycling of the ruthenium catalyst C18 was achieved in six consecutive cycles without loss of activity. Much better results were obtained with zwitterionic complexes $\mathbf{C 2 2 - C 2 7}$ bearing 
a $\mathrm{OSO}_{3}{ }^{-}$ligand (Figure 10). ${ }^{19}$ In particular, iridium catalyst C25 displayed high performances in aqueous phase transfer hydrogenation using formic acid (TON 9000) and more significantly in hydrogenation under 5 bar of hydrogen pressure at $130^{\circ} \mathrm{C}$, for which the highest TON was reported (TON 174000). Of note, it was demonstrated that transfer hydrogenation proceeded essentially by hydrogenation resulting from fast and efficient dehydrogenation of formic acid into $\mathrm{CO}_{2}$ and $\mathrm{H}_{2}$.

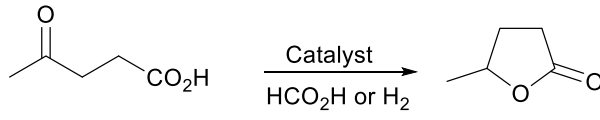

levulinic acid

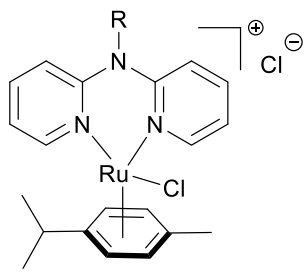

$\mathrm{R}=\mathrm{H}: \mathbf{C 1 6}, \mathrm{Bz}: \mathbf{C 1 7}, \mathrm{CH}\left(\mathrm{CH}_{3}\right) \mathrm{Ph}: \mathbf{C} 18$

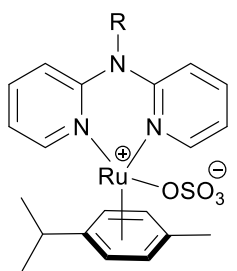

$\mathrm{R}=\mathrm{H}: \mathbf{C 2 2}, \mathrm{Bz}: \mathbf{C 2 3}, \mathrm{CH}\left(\mathrm{CH}_{3}\right) \mathrm{Ph}: \mathbf{C 2 4}$
GVL

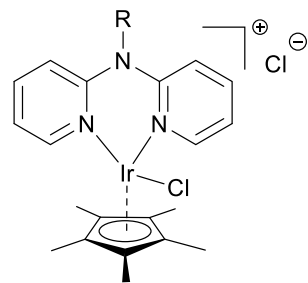

$\mathrm{R}=\mathrm{H}: \mathbf{C 1 9}, \mathrm{Bz}: \mathbf{C 2 0}, \mathrm{CH}\left(\mathrm{CH}_{3}\right) \mathrm{Ph}: \mathbf{C 2 1}$

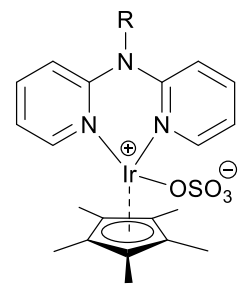

$\mathrm{R}=\mathrm{H}: \mathbf{C 2 5}, \mathrm{Bz}: \mathbf{C 2 6}, \mathrm{CH}\left(\mathrm{CH}_{3}\right) \mathrm{Ph}: \mathbf{C 2 7}$

Figure 10 Reduction of levulinic acid into $\gamma$-valerolactone (GVL)

The zwitterionic iridium-complex C25 was further engaged in the reductive amination of levulinic acid into pyrrolidone derivatives (Scheme 2$)^{20}$

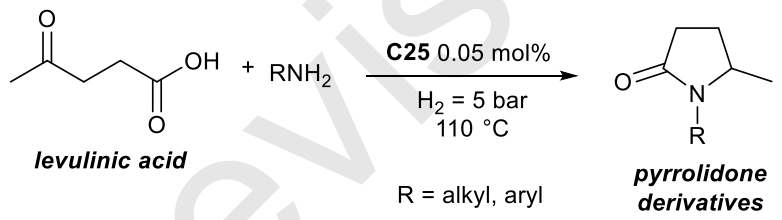

Scheme 2 Reductive amination of levulinic acid

A broad range of pyrrolidone derivatives was efficiently synthesized from aliphatic and aromatic amines. In particular, sterically hindered amines could be employed leading to new bulky derivatives as shown in Figure 11. Isoindolinone derivatives were also efficiently prepared by reductive amination of 2formylbenzoic acid. Here too bulky derivatives including new compounds were also prepared in high yields (Figure 11). 


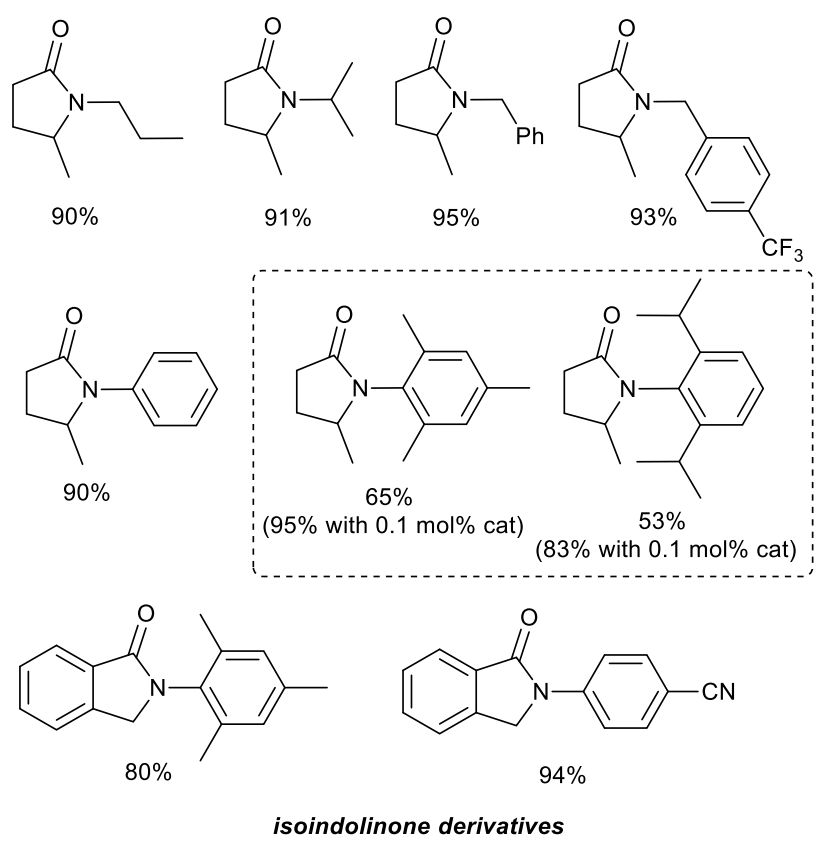

Figure 11 Biosourced pyrrolidone and isoindolinone derivatives

The hydrogenation of another biosourced compound, namely 5-hydroxymethylfurfural (HMF), into 1hydroxyhexane-2,5-dione (HHD) was reported by de Vries (Figure 12). ${ }^{21}$ Among five catalysts evaluated, the iridium-dpa C19 furnished the highest yield of 76\%. Notably, the well-know and efficient Ru-pincer catalyst C28 led to high conversion but poor selectivity for the desired product isolated in only 5\%.

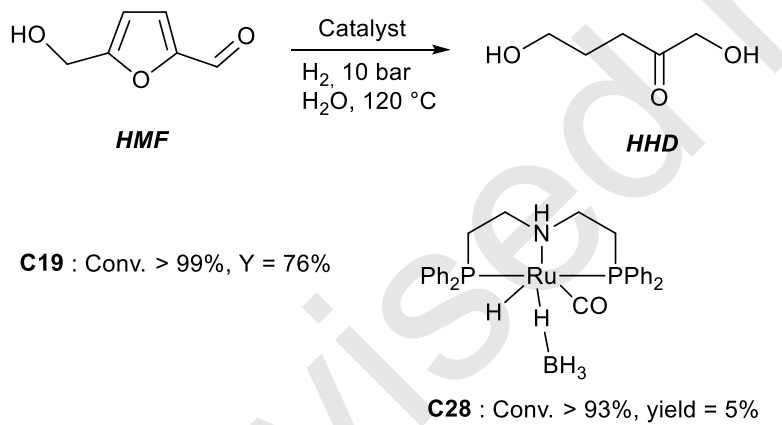

Figure 12 Reduction of HMF into HHD

\subsection{Oxidation reactions}

Beside reduction reactions, oxidation transformations involving dpa-ligands have received less attention. Early reports made use of dpa and dpa derivatives in ligand screening. In 1995, Griffith reported a study on the ruthenium- and osmium-catalysed oxidation of alkenes, alkanes and alcohols. ${ }^{22}$ Catalysts in situ generated from $\mathrm{RuCl}_{3}$ and various bidentate $\mathrm{N}, \mathrm{N}$ - ligands were evaluated in the epoxidation of cyclooctene using $\mathrm{NaIO}_{4}$ as oxidant. A modest $50 \%$ yield was obtained with $\mathrm{RuCl}_{3}-\mathrm{dpa}$ when $72 \%$ was obtained with $\mathrm{RuCl}_{3}$-bpy. Dpa ligands were implemented in the synthesis of supramolecular polynuclear metal catalysts for oxidation of 3,5-di-tert-butylcatechol (DTBC). ${ }^{23}$ In an example, the copper-catalyzed oxidation of DTBC in a pure oxygen atmosphere was performed at $25^{\circ} \mathrm{C}$. 
All the dpa-based catalysts displayed moderate conversion of ca. 45-50\% with selectivities for 3,5-ditert-butylbenzoquinone higher than $90 \%$. In another example, eight dpa ligands were anchored onto a silsesquioxane cage. ${ }^{24}$ Three of these dpa could be coordinated to a molybdenum species leading to a silsesquioxane "T8-dpa-[Mo $\left.\left(\eta^{3}-\mathrm{C}_{3} \mathrm{H}_{5}\right) \mathrm{Br}(\mathrm{CO})_{2}\right]$ " supramolecular architecture. This compound was fully characterized and evaluated in the epoxidation of styrene and cyclooctene using tert-butyl hydroperoxide (TBHP) as oxidant, but it exhibited low reactivity. In another study, $\left[\mathrm{Cu}(\mathrm{II})(\mathrm{dpa})\left(\mathrm{H}_{2} \mathrm{O}\right)_{3}\right]^{2+}$ was advantageously used for the selective delignification of oxygen-prebleached Kraft pulp (OPK) using $\mathrm{H}_{2} \mathrm{O}_{2}{ }^{25}$ When compared to ligand-free $\mathrm{CuCl}_{2}$ bleaching, the $\mathrm{Cu}(\mathrm{II})(\mathrm{dpa})$ catalyst led to a 12 -fold increase of the delignification selectivity. This improvement was assumed to result from the measured decrease of hydroxyl radical in reaction catalysed by $\mathrm{Cu}(\mathrm{II})(\mathrm{dpa})$ as compared to $\mathrm{CuCl}_{2}$.

In 2004, Bolm reported a study aimed at using dpa-ligands in stereoselective copper-catalyzed allylic oxidation of cyclohexene (Scheme 3). ${ }^{26} \mathrm{~A}$ series of C1- and C2-symmetric ligands were prepared by Pdcatalyzed amination reactions. Among the numerous ligands prepared, the C1-symmetric ligand $\mathbf{L} 8$ exhibited the best performances but the ee remained low (17\%).

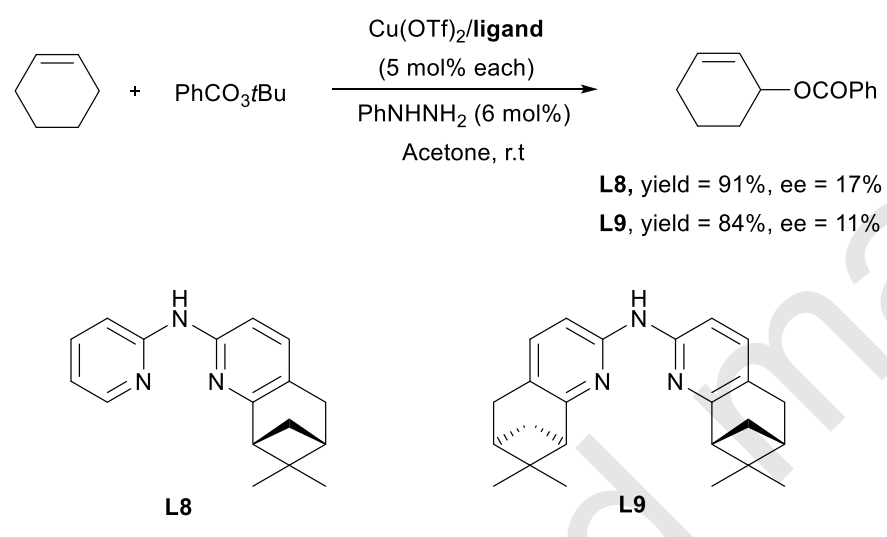

Scheme 3 Copper-catalysed allylic oxidation of cyclohexene

The straightforward functionalisation of the bridging $\mathrm{NH}$ of dpa was used for the immobilisation of a Pdcatalyst in water. A PEG-tagged dpa ligand was prepared and coordinated to $\mathrm{Pd}(\mathrm{OAc})_{2} \cdot{ }^{27}$ The resulting catalyst C29 was used for the aqueous phase aerobic oxidation of styrene resulting in the selective formation of benzaldehyde in $82 \%$ yield along with acetophenone, benzoic acid and other unidentified compounds (Scheme 4). This catalyst led to better performances than other palladium catalysts coordinated with other $\mathrm{N}$-ligands. It is noteworthy that the catalyst could be reused up to 7 times without alteration of its performances. 

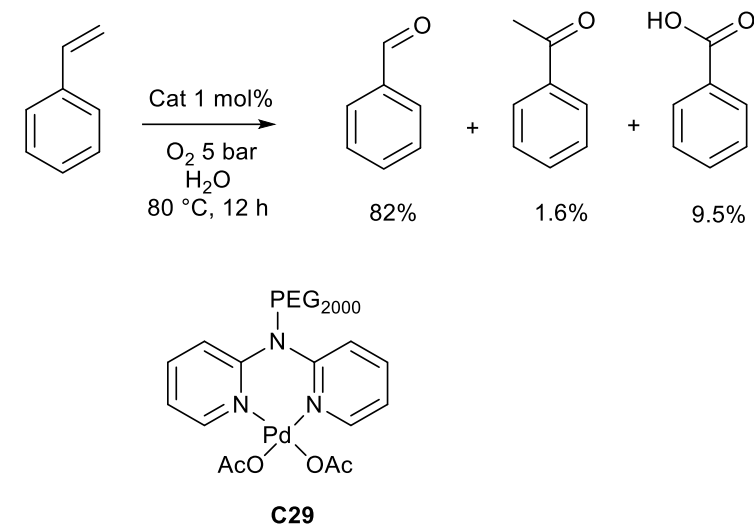

Scheme 4 Aqueous phase oxidation of styrene

The catalytic properties of the $[\mathrm{Cp} * \operatorname{Ir}(\mathrm{dpa}) \mathrm{Cl}] \mathrm{Cl}$ complex $\mathbf{C 1 9}$ (Figure 10) were investigated in the very challenging and important water oxidation reaction driven by Cerium Ammonium Nitrate (CAN). ${ }^{28}$ Not only did this catalyst perform better than the bipyridine-based catalyst $[\mathrm{Cp} * \operatorname{Ir}(\mathrm{bpy}) \mathrm{Cl}] \mathrm{Cl}$ but it exhibited a peculiar behaviour as CAN was always consumed faster than $\mathrm{O}_{2}$ evolution. An extreme situation was found with a CAN/Cat ratio of 80 for which CAN was almost fully consumed before $\mathrm{O}_{2}$ evolution began. The authors assumed that the bridging $\mathrm{NH}$ moiety of the dpa ligand might be responsible for the easier oxidative degradation of $\mathbf{C 1 9}$ leading to more active catalytic sites as reported by Fukuzumi. ${ }^{29}$ Based on kinetic and DFT studies, the authors proposed an alternative pathway involving the formation and transfer of an O-O bond containing moiety from Ir to Ce species followed by oxygen release. Yet in the domain of sustainable energy sources, an electron-enriched iridium complex $\mathbf{C 3 0}$ was prepared and evaluated in the dehydrogenation of formic acid (Scheme 5). ${ }^{30}$ This catalyst achieved a TOF of 12321 at $\mathrm{pH}$ 1.8. Contrasting with most iridium-based catalysts which exhibited their best performances at $\mathrm{pH}$ 3.5-4 (i.e. pKa of formic acid), C30 performed best at a pH 1.8 (i.e. no added sodium formate). It was also demonstrated that $\mathbf{C} \mathbf{3 0}$ could maintain its performances within a concentration range going from $2 \mathrm{M}$ to $8 \mathrm{M}$. Noteworthy, the catalyst could be used in pure formic acid in which a TOF of $4800 \mathrm{~h}^{-1}$ was reached hence demonstrating the high stability of this catalyst in acidic media. Based on the comparative study of numerous catalysts bearing diversely substituted dpa ligands, the authors proposed a mechanism involving $\mathrm{H}$-bonding between formic acid and the proton of the bridging $\mathrm{NH}$. Another liquid organic hydrogen carrier (LHOC), namely tetrahydroquinoline, could be efficiently dehydrogenated in water by C30 leading to quinoline in $98 \%$ yield. ${ }^{31}$ Interestingly, the same catalyst was able to promote the reverse reaction under mild conditions of temperature and pressure (Scheme 4). This protocol was extended to numerous derivatives that could be efficiently converted in either way.

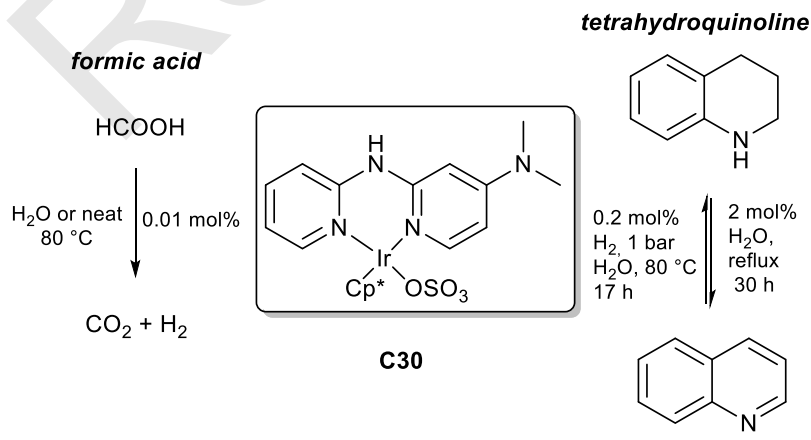

Scheme 5 Sustainable hydrogen storage and release 


\subsection{Olefin polymerisation}

The nickel complexes C31-C33 (Figure 13) are highly active catalysts for the oligomerization of ethylene into C4-C6 products. These complexes required initial activation by $\mathrm{Et}_{3} \mathrm{Al}_{2} \mathrm{Cl}_{3}$ in excess $(\mathrm{Al} / \mathrm{Ni}=600)$ and the reactions were performed at low temperature $\left(12-30^{\circ} \mathrm{C}\right)$ in dichloromethane under 0.6-1.3 bar for $1 \mathrm{~h}$. With the most efficient catalysts C32 and C33, turnover numbers of about 600000 were reached with major formation of the C4-C6 fraction including more than 90\% of butenes (C4-C6:C8-C16:>C16 ratio of 71:23:6 were obtained with $\mathbf{C 3 3}$ ). The oligomers were highly branched with a ratio of methyl protons to total alkyl protons of 0.61 for the higher boiling fraction. ${ }^{32}$

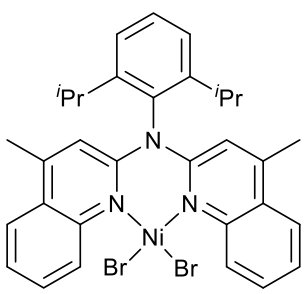

C31

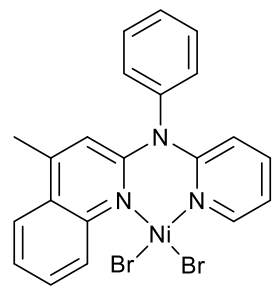

C32

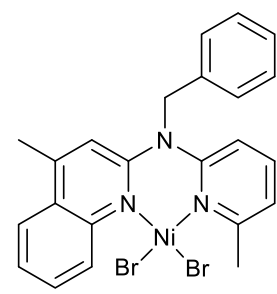

C33

Figure 13: Nickel(II) complexes used in ethylene oligomerization

When the binuclear $\mathrm{Ni}(\mathrm{II})$ complexes C34-C38 (Figure 14) were associated with alkylaluminium reagents in ethylene oligomerization conditions, an excellent activity was obtained when $\mathrm{Et}_{2} \mathrm{AICl}$ was used whereas methylaluminoxane led to an inefficient catalytic system. Thus, with an $\mathrm{Al} / \mathrm{Ni}$ ratio of 250 , a catalytic activity leading to the production of $499-662 \mathrm{~kg}$ of oligomers $/ \mathrm{mol}$ of nickel/h under 5 bar of ethylene at $30{ }^{\circ} \mathrm{C}$ was achieved corresponding to a TOF located in the range 18000-24000 h-1. Remarkably, under these conditions only butenes ( $\mathrm{C} 4$ fraction) were formed and catalyst $\mathbf{C} 3 \mathbf{8}$ proved to be very selective affording the terminal 1-butene with $98 \%$ selectivity. ${ }^{33}$ The mononuclear cationic palladium(II) complexes C39-C43 (Figure 14) were prepared with the same 2,2'-dipyridylamine ligands and evaluated in ethylene oligomerization. Without any cocatalyst, these palladium species oligomerised ethylene at $25^{\circ} \mathrm{C}$ in dichloromethane under 5 bar of ethylene. However, if the selectivity towards the formation of butenes was good, the productivity was low (TOF= 4.4 to $\left.7.4 \mathrm{~h}^{-1}\right) .{ }^{34}$

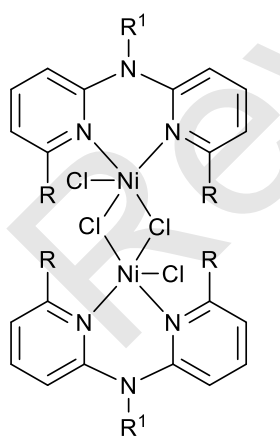

C34: $\mathrm{R}^{1}=\mathrm{Me}, \mathrm{R}=\mathrm{H}$ C35: $\mathrm{R}^{1}=\mathrm{Bn}, \mathrm{R}=\mathrm{H}$ C36: $R^{1}=M e C y, R=H$ C37: $R^{1}=\mathrm{Np}, \mathrm{R}=\mathrm{H}$ C38: $R^{1}=M e, R=M e$

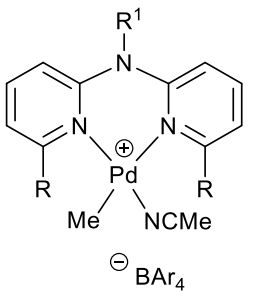

C39: $R^{1}=M e, R=H$

C40: $\mathrm{R}^{1}=\mathrm{Bn}, \mathrm{R}=\mathrm{H}$

C41: $\mathrm{R}^{1}=\mathrm{MeC}, \mathrm{R}=\mathrm{H}$

C42: $R^{1}=\mathrm{Np}, \mathrm{R}=\mathrm{H}$

C43: $R^{1}=M e, R=M e$

Figure 14 Nickel(II) and palladium(II) complexes used in ethylene dimerization

It is noteworthy that 1-octene or 1-hexene as sole olefin were formed together with low molecular weight polyethylene wax when ethylene ( 40 bar) was treated at high temperature $\left(>80^{\circ} \mathrm{C}\right)$ with 400 equivalents of methylaluminoxane in the presence of chromium complexes equipped with differently 
substituted dipyridylamine ligands as exemplified in Scheme $6 .{ }^{35}$ This selectivity was ascribed to steric factors, the less hindered ligands around the metal center such as $\mathbf{C 4 5}$ producing 1-octene.

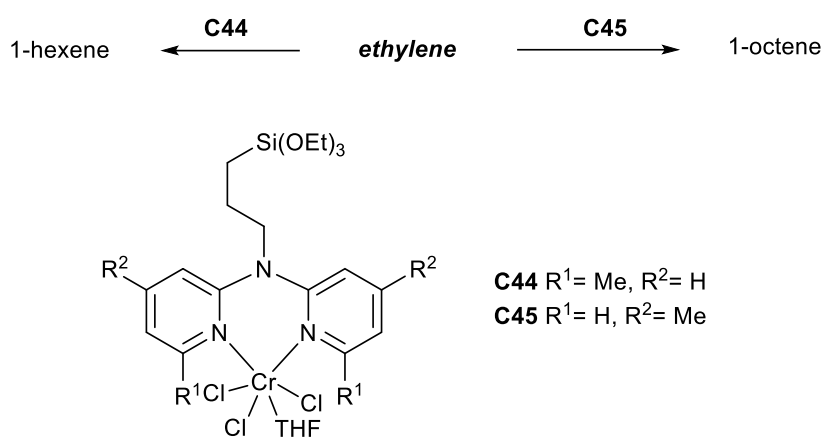

Scheme 6 Influence of steric hindrance of the dpa ligand on ethylene oligomerization

One or two dipyridylamine moieties connected to a polyethylene glycol chain in L10 and L11 were used in atom transfer radical polymerization of methyl methacrylate associated with a copper(II) halide $\left(\mathrm{CuBr}_{2}\right.$ or $\mathrm{CuCl}_{2} .2 \mathrm{H}_{2} \mathrm{O}$ ) as metal catalyst precursor (Figure 15). The polymerization reactions were carried out under thermo-regulated phase-transfer catalysis conditions using a water-toluene mixture as solvent. The copper-dpa catalyst was maintained in the aqueous phase at room temperature and transferred into the organic phase during the polymerization process at $90{ }^{\circ} \mathrm{C}$. After cooling the catalyst was recovered in the aqueous phase and polymethacrylate was extracted from the organic phase. ${ }^{36}$<smiles>CCCOCCCN(c1ccccn1)c1ccccn1</smiles>

L10<smiles>CC(C)CCOCCOCCN(CCOCCN(c1ccccn1)c1ccccn1)c1ccccn1</smiles>

Figure $15 \mathrm{~N}$-methoxypoly(ethyleneglycol)-dipyridyl L10 and polyethyleneglycol-supported-dipyridyl Ligand (PSDL) L11

Dipyridylamines have also been supported on polynorbornene obtained by ring opening metathesis of a functionalized norbornene with a molybdenum catalyst and on coated silica. When these materials were loaded with $\mathrm{CuBr} . \mathrm{Me}_{2} \mathrm{~S}$ or $\mathrm{Cu}(\mathrm{OAc})_{2} / \mathrm{Al}\left(\mathrm{O}^{\prime} \mathrm{Pr}\right)_{3}$, styrene could be polymerized in moderate yields $(<$ $25 \%$ ) following an atom transfer radical polymerization process initiated by ethyl-2-bromoisobutyrate. ${ }^{37}$ The cationic cobalt(III) complex [Co((L1) $\left.\left.)_{2}\right) \mathrm{Me}_{2}\right]$ I C46 (Figure 16) proved to be an excellent catalyst for the polymerization of acrylonitrile in methanol in the presence of $\mathrm{NaBH}_{4}$. It was shown that this polymerization did not involve a radical or an anionic mechanism but a coordination-type mechanism, 
where the borohydride reduced the cobalt(III) complex into a catalytically active cobalt(I) species able to coordinate the acrylic double bond and favor successive insertions into a Co-C bond. ${ }^{38}$

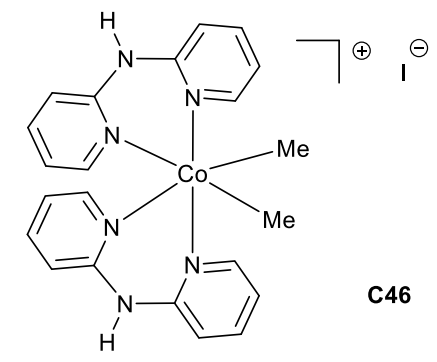

Figure 16 Cobalt(III) bis(L1) complex C46

Finally, the rhodium complex $[\mathrm{Rh}(\operatorname{cod})(\mathrm{L} 1)] \mathrm{PF}_{6}$ was used in the polymerization of alkynes such as phenylacetylene and the functional $\mathrm{N}$-propargylamine. ${ }^{39}$ Its catalytic properties in the formation of polyolefins from alkynes has been compared with other rhodium complexes equipped with other bidentate dinitrogen ligands such as 2,2'-bipyridine $\mathbf{L 2}$, 2,2' -bipyrazine and 4,4'-dimethyl-2,2'-bipyridine, and associated with other counter anions. It was shown that the nature of the ligands, counter anion as well as the presence of $\mathrm{NaOH}$ as cocatalyst had an influence on the fate of the polymerization. In both cases, polymerization of phenylacetylene and $\mathrm{N}$-propargylamine, the $[\mathrm{Rh}(\operatorname{cod})(\mathbf{L} \mathbf{1})] \mathrm{PF} \mathrm{F}_{6}$ complex exhibited better performances than the corresponding $\left[\mathrm{Rh}(\operatorname{cod})\left(\mathbf{L 2}_{2}\right)\right] \mathrm{PF} \mathrm{F}_{6}$.

\subsection{Hydrolysis of esters}

The dicationic species $\left[\mathrm{Cu}(\mathrm{LI})\left(\mathrm{H}_{2} \mathrm{O}\right)_{2}\right]^{2+} \mathbf{C 4 7}$ was claimed as the first catalyst able to perform hydrolysis of unactivated esters such as methyl acetate at $25^{\circ} \mathrm{C}$ at pH 7 with a rate constant similar to that obtained with natural esterases such as chymotrypsin. ${ }^{40}$ The same copper complex was also able to hydrolyze formamides under neutral $\mathrm{pH}$ conditions but a higher temperature was required (Scheme 7). ${ }^{41}$

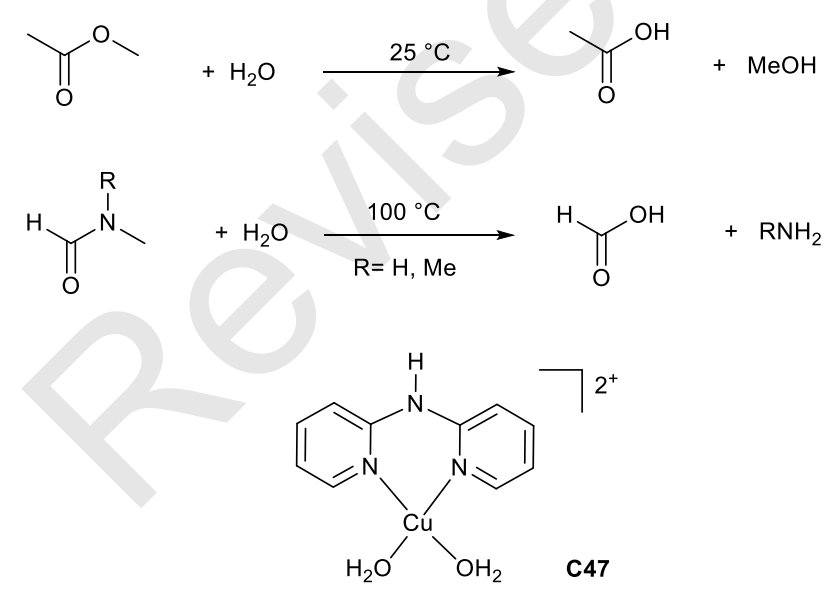

Scheme 7 Hydrolysis of esters and formamides in the presence of the copper(dipyridylamine) catalyst C47

Later on, the use of this type of copper catalyst was extended to more functionalized esters such as glycine ethyl ester, ${ }^{42}$ and other types of esters such as phosphotriesters. ${ }^{43}$

The carbonate protecting group of allyloxycarbonyl-coumarin has been removed upon treatment with phenylsilane in the presence of palladium-dipyridylamine catalysts such as C48 supported on polymer 
brushes (Scheme 8$){ }^{44}$ This system is operating as a reservoir of catalytic species that are progressively released in solution and the influence of the thickness of the surface has been studied in detail.
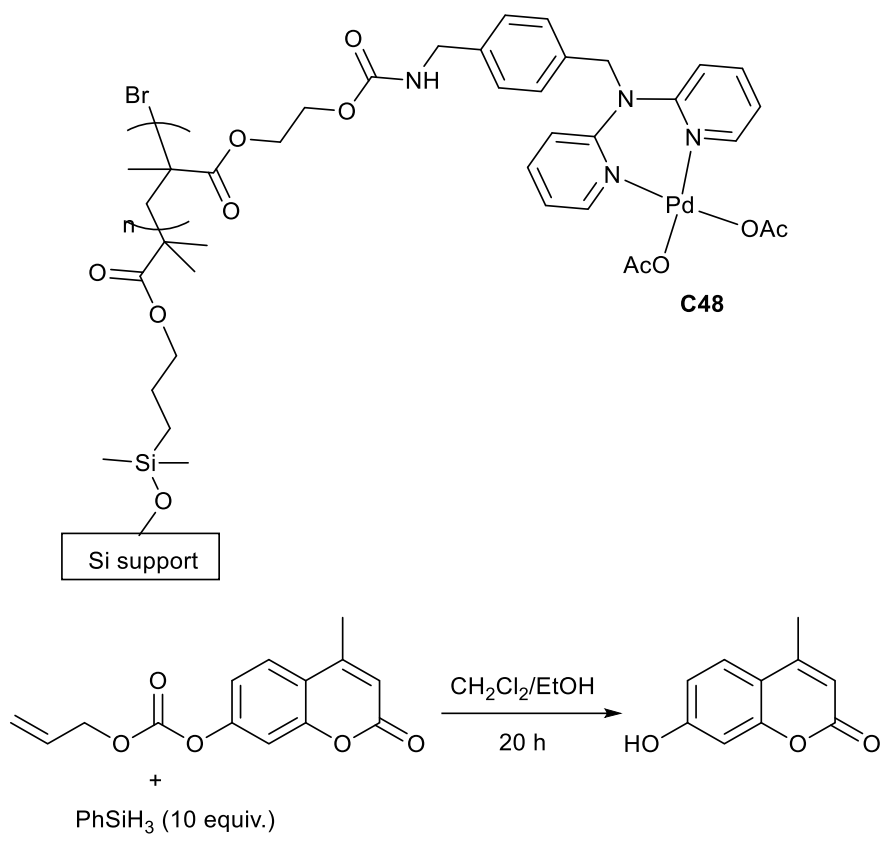

Scheme 8 Hydrolysis of carbonate by $\mathrm{PhSiH}_{3}$ in the presence of palladium(dpa) catalysts immobilized on welldefined polymer brushes

\subsection{Transesterification}

2,2'-Dipyridylamine (L1) has been coordinated to zinc, cadmium and mercury leading to various types of mononuclear complexes and polymeric forms, which have been evaluated in transesterification reactions. Thus, when $\mathrm{Zn}(\mathrm{OBz})_{2}(\mathrm{OBz}=$ benzoate) was reacted with $\mathbf{L} \mathbf{1}$, the monomeric complex $\mathrm{Zn}(\mathrm{OBz})_{2}(\mathbf{L 1})$ was formed, whereas $\mathrm{ZnBr}_{2}$ and $\mathrm{ZnCl}_{2}$ produced hydrogen-bonded $\mathrm{ZnX}_{2}(\mathbf{L 1})$ polymers. On the other hand, $\mathrm{Zn}\left(\mathrm{H}_{2} \mathrm{O}\right)_{2}(\mathbf{L 1})\left(\mathrm{SO}_{4}\right)$ was obtained as a coordination polymer from $\mathrm{Zn}\left(\mathrm{SO}_{4}\right)$ and $\mathbf{L} \mathbf{1}$. All these forms exhibited catalytic activity for the transesterification of various benzoates and acetates with methanol with a catalyst loading of 4 mol\% leading to complete conversion within 2-9 days into methyl benzoate and methyl acetate, respectively. ${ }^{45}$ The hydrogen-bonded $\left[\mathrm{ZnCl}_{2}(\mathbf{L} \mathbf{1})\right]$ heterogeneous system appeared to give the best efficiencies. Later on, it was shown that the introduction of a nitrate ligand in $\left[\mathrm{Zn}\left(\mathrm{NO}_{3}\right)(\mathbf{L 1})_{2}\right]\left[\mathrm{NO}_{3}\right]$ provided a more efficient catalyst. ${ }^{46}$ The substitution of zinc by cadmium has led to a variety of cadmium complexes featuring one, two or three dpa ligands. All of them were tested in transesterification reaction of acetates and benzoates with methanol and $\left[\mathrm{Cd}(\mathrm{L1})_{3}\right]\left[\mathrm{ClO}_{4}\right]_{2}$ offered the best catalytic activity. ${ }^{47}$ Notably, the mercury complexes $\mathrm{Hg}(\mathrm{OBz})_{2}(\mathbf{L 1})$ and $\mathrm{Hg}_{2}(\mathbf{L 1})_{2}\left(\mathrm{NO}_{3}\right)_{2}$ have also shown catalytic activity for transesterification reactions. ${ }^{48}$

\subsection{Cross coupling reactions}

There are only a few examples of application of 2,2'-dipyridylamine derivatives as ligands associated with palladium in cross coupling reactions and they are mostly devoted to catalysis in water or aqueous biphasic media.

Thermo-regulated systems have been reported, where the central nitrogen atom of the dpa (L12) is connected to a decyloctaethyleneglycol and coordinated to a palladium centre upon treatment with 
$\mathrm{Na}_{2} \mathrm{PdCl}_{4}$ to generate the neutral $\mathbf{C 4 9}$ and dicationic palladium complex $\mathbf{C 5 0}$ (Scheme 9). ${ }^{49}$ These complexes are readily prepared and show different solubility properties due to the presence of the amphiphilic ligand, the neutral $\mathbf{C 4 9}$ is insoluble in water whereas the ionic $\mathbf{C 5 0}$ is soluble. Heck reaction were carried out at $110-120{ }^{\circ} \mathrm{C}$ in biphasic aqueous media with in situ generated catalysts based on $\mathrm{Na}_{2} \mathrm{PdCl}_{4}$ and an excess of ligand. The organic phase consisted of the substrates without additional solvent. The catalytic reactions took place in this organic phase and after cooling the catalyst was transferred to the water phase and the products isolated from the organic phase. Starting from iodobenzene, E-cinnamic acid was isolated in $89 \%$ yield after $20 \mathrm{~h}$ from ethyl acrylate, whereas trans-stilbene was recovered in more than $90 \%$ yield after $40 \mathrm{~h}$ from styrene. The catalyst recovered in the aqueous phase could be reused but its activity decreased probably because of accumulation of salts in this phase.

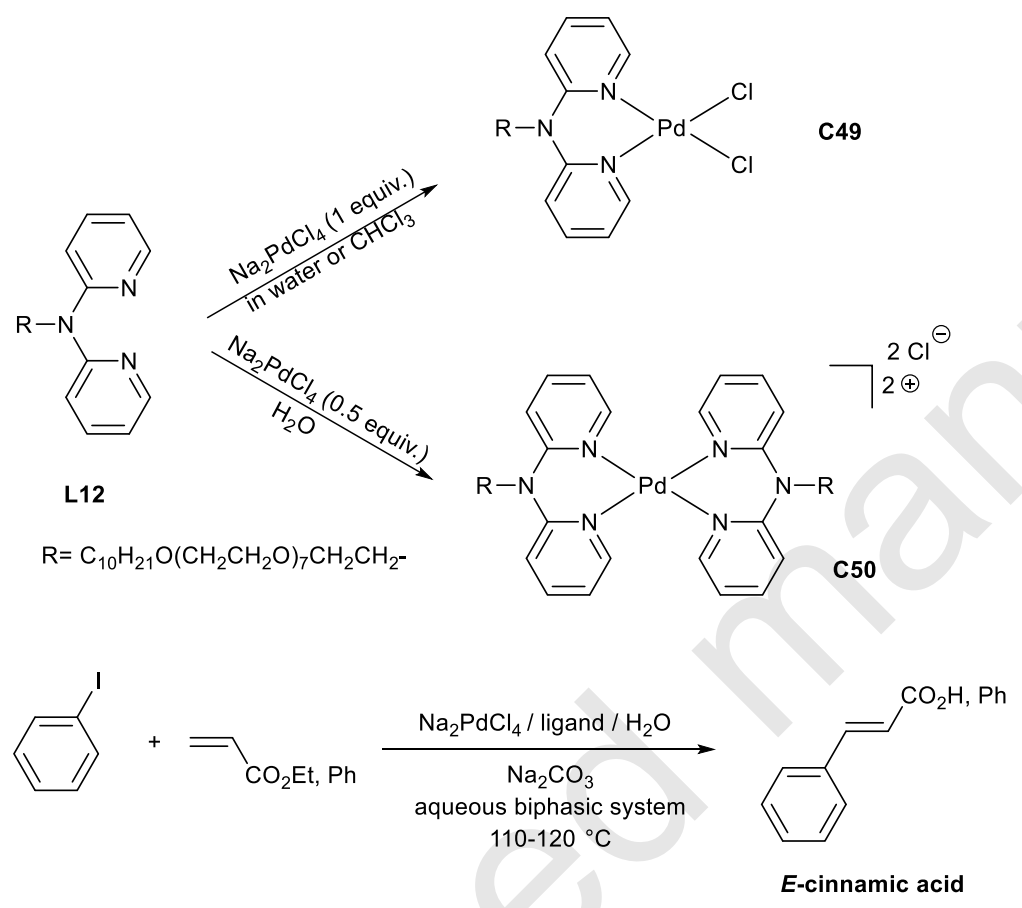

Scheme 9 Heck cross coupling with thermo-regulated catalytic systems

The copper-free Sonogashira coupling was also performed efficiently at room temperature in water with an in situ generated catalyst based on equimolar amounts of $\mathrm{Pd}\left(\mathrm{NH}_{3}\right)_{2} \mathrm{Cl}_{2}$ as metal precursor and $\mathbf{L 1}$ as bidentate ligand (Scheme 10). ${ }^{50}$ The reaction required the presence of triethylamine as a base, other organic amines such as diisopropylamine or tributylamine being inefficient as well as the classical $\mathrm{KOH}$, $\mathrm{NaOAc}, \mathrm{K}_{3} \mathrm{PO}_{4}, \mathrm{CS}_{2} \mathrm{CO}_{3}$. In this study, it was shown that the dipyridylamine ligand triggered much higher catalytic activity than other bidentate nitrogen ligands such as 2,2'-bipyridine $\mathbf{L} 2,1,10$-phenanthroline L3, 2-imidazol-2-ylpyridine and 2-pyrazol-3-ylpyridine. The cross-coupling reaction of phenylacetylene and electron-enriched phenylacetylenes with various phenyl iodides gave more than $73 \%$ yield of the corresponding 1,2-diarylacetylenes whereas lower yields located in the range $59-73 \%$ were obtained with the electron-deficient 4-acetylphenylacetylene. 


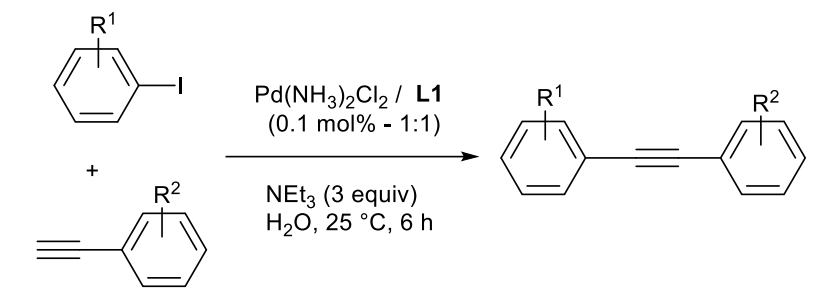

$\mathrm{R}^{1}=\mathrm{H}, 4-\mathrm{Cl}, 4-\mathrm{CF}_{3}, 4-\mathrm{F}, 2-\mathrm{Me}, 3-\mathrm{Me}, 4-\mathrm{Me} ; \mathrm{R}_{2}=\mathrm{H}, 4-\mathrm{MeO}, 2-\mathrm{Me}, 3-\mathrm{Me}, 4-\mathrm{Me}: \mathrm{Y}=73-100 \%$ $\mathrm{R}^{1}=\mathrm{H}, 4-\mathrm{CF}_{3}, 2-\mathrm{Me}, 3-\mathrm{Me}, 4-\mathrm{Me} ; \mathrm{R}_{2}=4-\mathrm{MeCO}: \mathrm{Y}=59-73 \%$

Scheme 10 Sonogashira coupling promoted by a L1-containing palladium catalyst

The Suzuki-Miyaura coupling was also achieved in water with palladium complexes equipped with ionic water soluble dipyridylamine ligands. These complexes were obtained by treatment of $\mathrm{Pd}(\mathrm{OAc})_{2}$ with equimolar amounts of ligands L13-L15 in dichloromethane (Scheme 11)..$^{51}$

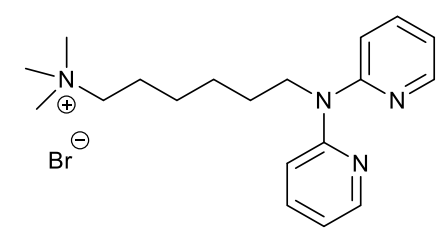

L13

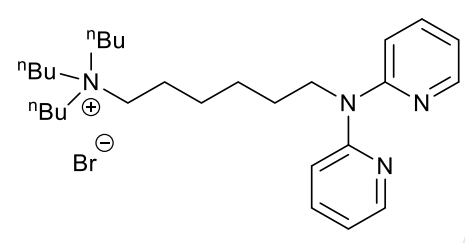

L14

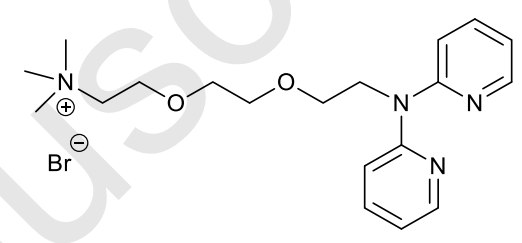

L15

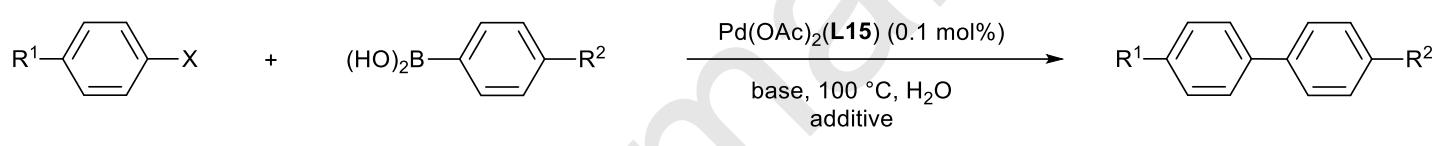

$\mathrm{X}=\mathrm{Br}, \mathrm{R}^{1}=4-\mathrm{COMe}, 4-\mathrm{CHO}, 4-\mathrm{CO}_{2} \mathrm{H}, 4-\mathrm{CN} ; \mathrm{R}_{2}=\mathrm{H} \quad$ quantitative $\mathrm{GC}$ yield $\mathrm{X}=\mathrm{Cl}, \mathrm{R}^{1}=4-\mathrm{COMe}, 4-\mathrm{NO}_{2}, 4-\mathrm{OMe} ; \mathrm{R}_{2}=\mathrm{H}, 4-\mathrm{CHO}, 4-\mathrm{F}, 4-\mathrm{Me}, 4-\mathrm{OMe} \quad>76 \%$ GC yield

Scheme 11 Suzuki-Miyaura coupling in water soluble palladium catalysts based on ionic dipyridylamines

$\mathrm{Pd}(\mathrm{OAC})_{2}(\mathrm{~L} 15)$ was the most active catalyst for the cross coupling of aryl bromides and chlorides with arylboronic acids indicating a clear effect of the pendant ionic group of the ligands. A turnover frequency of $96000 \mathrm{~h}^{-1}$ was reached during the coupling of 4-bromoacetophenone and phenylboronic acid at 100 ${ }^{\circ} \mathrm{C}$ in water in the presence of $0.001 \mathrm{~mol} \%$ of this catalyst leading to $96 \%$ yield of 4 -acetylbiphenyl within $1 \mathrm{~h}$. Arylbromides containing electron-withdrawing groups in 4-position gave the cross coupling products in excellent yields in short reaction times (less than $1 \mathrm{~h}$ ) with $0.1 \mathrm{~mol} \%$ catalyst loading. In addition, the catalyst tolerated the presence of withdrawing and donating functional groups in the arylboronic acid partner without loss of reactivity. Starting from arylchlorides required more drastic conditions including longer reaction times and the presence of a phase transfer agent such as tetra- $n$-butylammonium bromide. In these systems, nanoparticles with small size and narrow size distribution stabilized by the ionic dipyridylamine ligands were detected at the end of the reactions.

Ring opening copolymerization of (Z)-9-oxabicyclo[6.1.0]non-4-ene with tris(cyclooct-4-enyl-1oxy)methylsilane with a Grubbs third generation ruthenium catalyst has been used to prepare palladium nanoparticles embedded in the pores of a polymeric support (Scheme 12). ${ }^{52}$ This material C51 has shown catalytic activity for the Suzuki-Miyaura cross coupling of bromobenzene derivatives with phenylboronic acid at $50^{\circ} \mathrm{C}$ for $24 \mathrm{~h}$ in water in the presence of ${ }^{\mathrm{B}} \mathrm{BuOK}$ as a base and tetra- $n$-butylammonium bromide as phase transfer agent. Assuming that only the surface palladium atoms participated in the catalytic reaction, turnover numbers up to 2940 were reached. On the other hand, this catalyst was much less 
efficient for the copper-free cross coupling of the same bromobenzene substrates with phenylacetylene at $80{ }^{\circ} \mathrm{C}$ leading to a moderate $36 \%$ yield, whereas iodobenzene proved to be much more reactive providing 95\% yield upon reaction with 2,4,6-trimethylphenylacetylene.
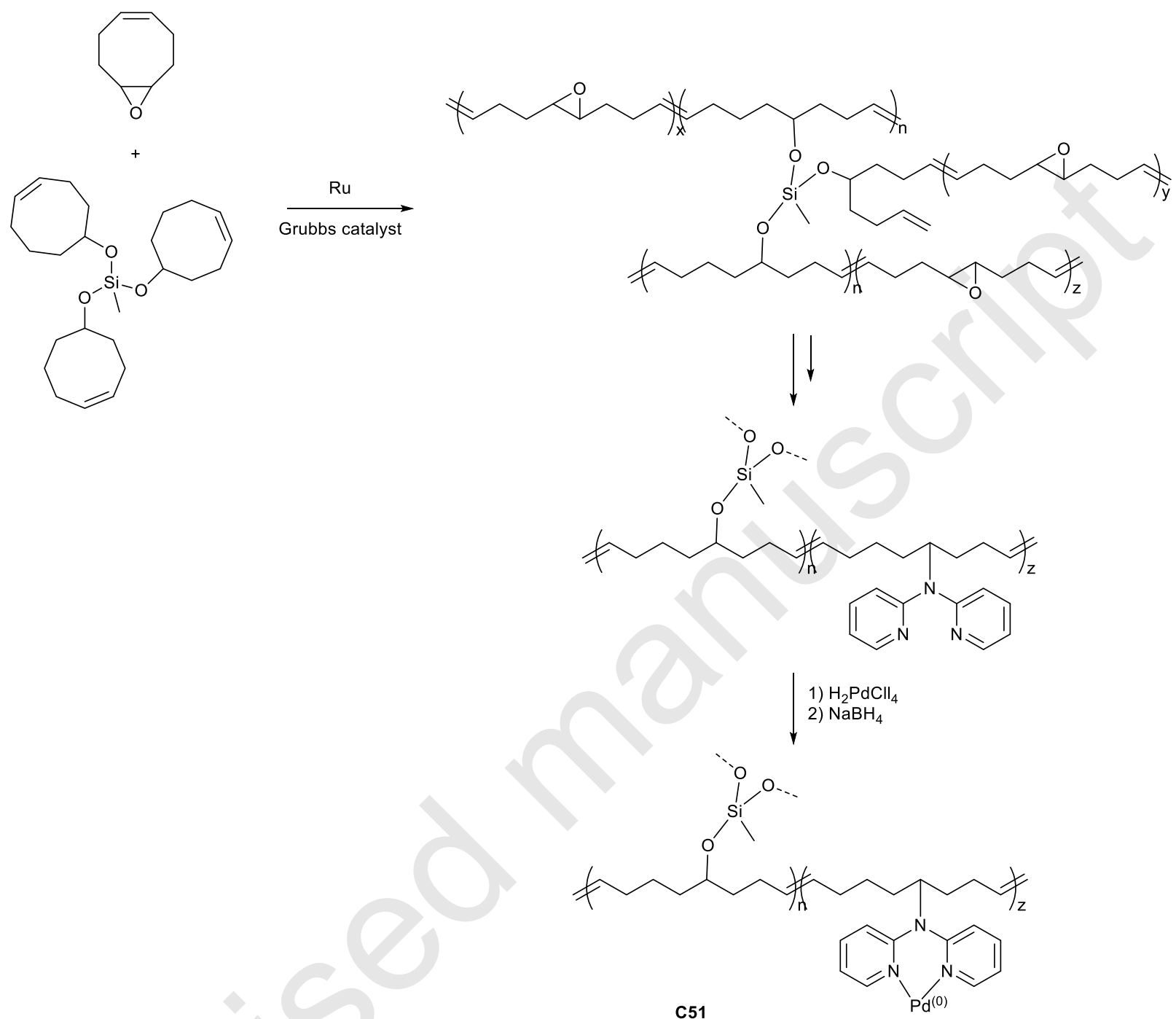

Scheme 12 Palladium nanoparticles immobilized within small pores functionalized by dipyridylamine groups

Finally, nickel species generated in situ from equimolar amounts of $\mathrm{NiBr}_{2} .3 \mathrm{H}_{2} \mathrm{O}$ and $\mathbf{L} \mathbf{1}$ have been used for the reductive coupling of aryl halides in ethanol at room temperature under electrolysis conditions at a constant current of $0.6 \mathrm{~A} \cdot \mathrm{dm}^{-2}$ (Scheme 13). Under similar conditions, the reductive cross coupling of arylbromides with electron-deficient olefins such as acrylates and ethyl maleate was also achieved in good yield, whereas acrylonitrile and ethyl methacrylate were not reactive (Scheme 13). ${ }^{53}$ 

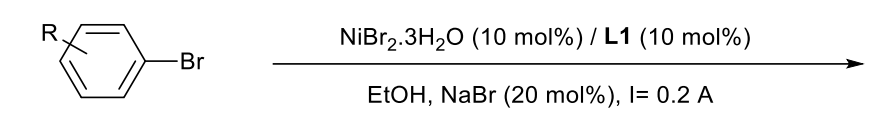

EtOH, $\mathrm{NaBr}(20 \mathrm{~mol} \%), \mathrm{l}=0.2 \mathrm{~A}$

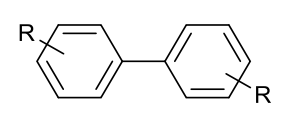

$\mathrm{R}=\mathrm{H}(95 \%), 4-\mathrm{F}(90 \%), 4-\mathrm{MeO}(32 \%)$, $4-\mathrm{CF}_{3}(90 \%), 4-\mathrm{MeCO}(63 \%)$,

$4-\mathrm{NMe}_{2}(30 \%), 2-\mathrm{Me}(43 \%), 2-\mathrm{F}(68 \%)$

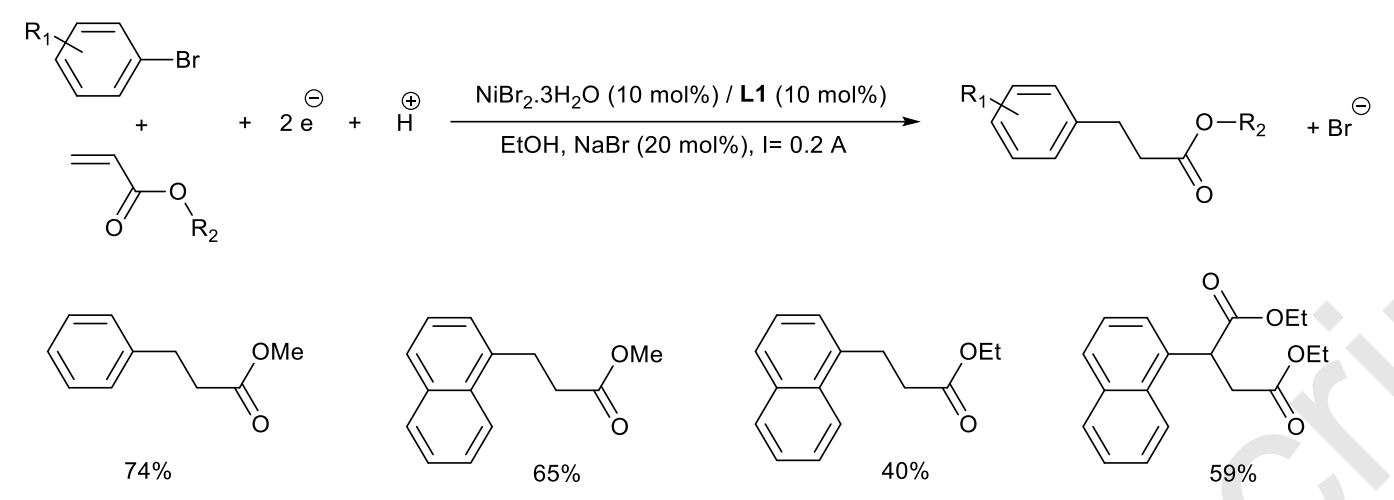

Scheme 13: Electroreductive cross couplings with an in situ generated nickel catalyst

Dipyridylamine copper complexes have been used as catalysts for the oxidative coupling of 2,6-dimethylphenol. Depending on the nature of the catalyst precursor and the experimental conditions, 3,3',5,5'-tetramethyl-4,4'-diphenoquinone (DPQ) and poly(2,6-dimethyl-1,4-phenylenether) (PPE) could be formed (Scheme 14). Under mild conditions, e.g. $25^{\circ} \mathrm{C}$ under atmospheric pressure of dioxygen in a methanol/toluene mixture as solvent, the copper complex C52 (catalyst loading: 0.4 mol\%) led to the selective formation of the PPE polymer. ${ }^{54}$

The oxidation of 2,6-dimethylphenol was also studied with $\mathrm{H}_{2} \mathrm{O}_{2}$ as oxidant and the copper complex with the proposed structure $\mathbf{C} 53$ as catalyst in aqueous buffer in the range of $\mathrm{pH} 6.0-9.0$ at $25^{\circ} \mathrm{C}$. It was shown that the $\mathbf{L} \mathbf{1}$ ligand provided the most efficient catalyst and that the initial rate of formation of DPQ strongly depended on the value of the $\mathrm{pH}$, the maximum being located around $\mathrm{pH} 7 .{ }^{55}$ The introduction of surfactants in the reaction medium such as cetyl trimethylammonium bromide leading to the formation of micelles had a beneficial effect on the rate of oxidation of 2,6-dimethylphenol and favored the formation of PPE polymer. ${ }^{56}$ 


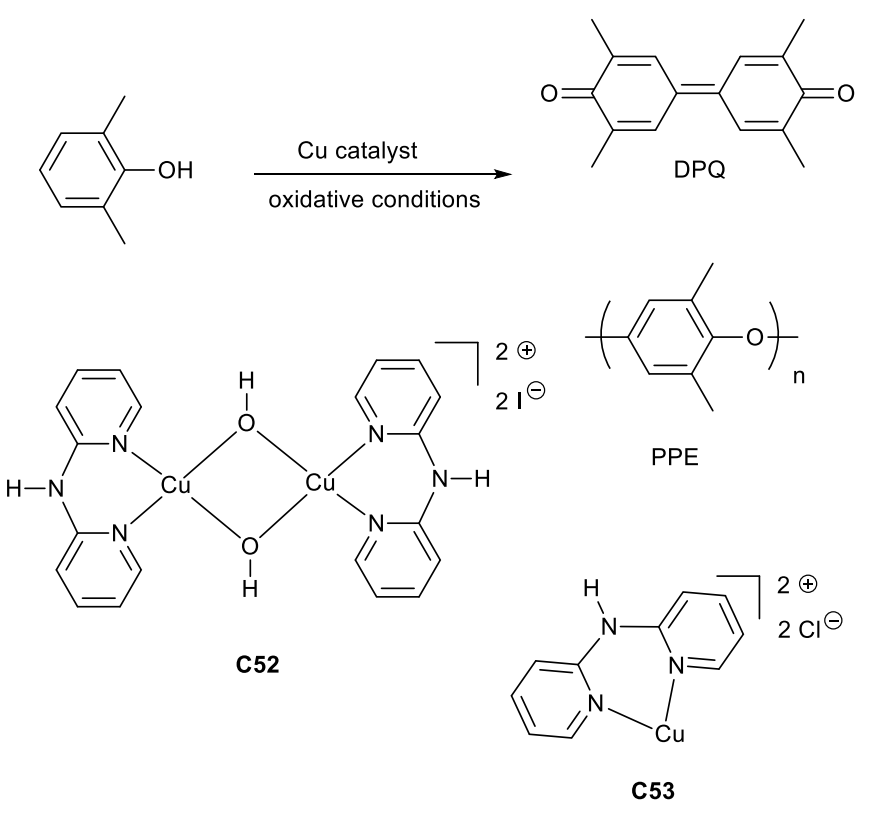

Scheme14 Oxidative coupling of 2,6-dimethylphenol with copper catalysts

\subsection{Miscellaneous reactions}

\section{Photocatalyzed aza-Henry reaction}

Among a series of cationic iridium complexes featuring two $\mathrm{N}, \mathrm{C}$-cyclometallated ligands based on benzoquinoline, 2-phenylisoquinoline, and dpa L1, the iridium complex C54 has revealed efficient catalytic properties for the photocatalyzed aza-Henry reaction involving $\mathrm{N}$-phenyltetrahydroisoquinoline and nitromethane (Scheme 15$) \cdot{ }^{57}$ In the presence of $1 \mathrm{~mol} \%$ of catalyst C54, full conversion of the aromatic substrate was achieved and $69 \%$ of product resulting from selective $\mathrm{sp}^{3} \mathrm{C}-\mathrm{H}$ bond activation/functionalization at the benzylic position of the tetrahydroisoquinoline ring was obtained at room temperature under air within $11 \mathrm{~h}$. This result competes with the $79 \%$ isolated yield obtained with the more active [Ir(2-phenylpyridine) ${ }_{2}$ (di-tert-butylbipyridine)][PF$\left.F_{6}\right]$ catalyst used for comparison.

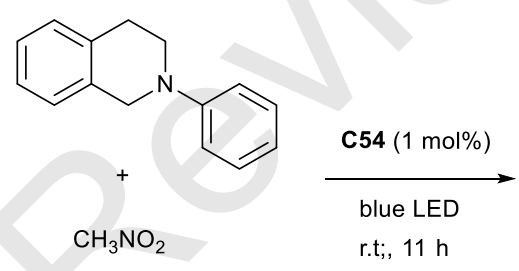<smiles>O=[N+]([O-])CC1c2ccccc2CCN1c1ccccc1</smiles>

$69 \%$

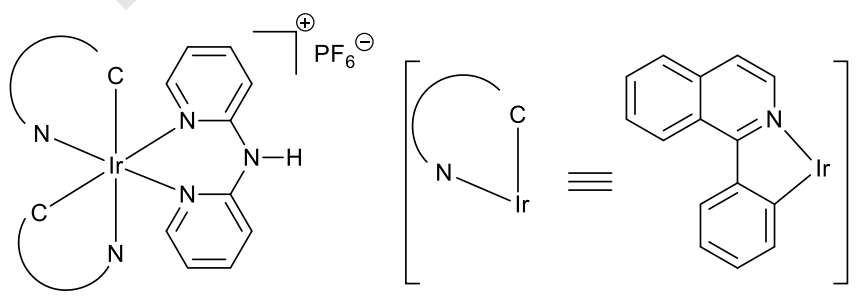

C54

Scheme 15 Aza-Henry reaction photocatalyzed by the iridium catalyst C54 


\section{Hydroformylation of olefins}

Very early on, 2,2'-dipyridylamine $\mathbf{L} \mathbf{1}$ has been used in hydroformylation of olefins for comparison purposes with other bidentate nitrogen ligands such as 2,2'-bipyridine $\mathbf{L 2}, \mathbf{1}, \mathbf{1 0}$-phenanthroline $\mathbf{L} 3$. For instance the hydroformylation of 1-octene at $180^{\circ} \mathrm{C}$ with a pressure of $\mathrm{CO} / \mathrm{H}_{2}$ (1:2 ratio) of 80 bar in the presence of $3 \mathrm{~mol} \%$ of $\mathrm{RuO}_{2}-\mathrm{L} 1$ as catalyst precursor, led to a mixture of branched and linear nonanals and nonanols with major formation of alcohols, and a reactivity and selectivity comparable to the results obtained with bipyridine ligands. ${ }^{58}$ On the other hand, the catalytic species generated from $\mathrm{Ru}_{3}(\mathrm{CO})_{12}$ and $\mathbf{L} \mathbf{1}$ on silica carrier was active in hydroformylation of 1-hexene at $150^{\circ} \mathrm{C}$ under 50 bar of syngas and led to heptanals as major products but the productivity remained lower than when bipyrine was used. ${ }^{59}$

\section{Photoluminescent materials}

A rapid survey of the literature shows that around 700 complexes bearing dipyridylamine derivatives as ligand are reported in the literature. These include chromium, ${ }^{60}$ molybdenum, ${ }^{61}$ manganese, ${ }^{62}$ rhenium, ${ }^{63}$ iron, $^{64}$ ruthenium, ${ }^{65}$ osmium, ${ }^{65,66}$ cobalt, ${ }^{67}$ rhodium, ${ }^{65 c}$ iridium, ${ }^{65 c, 67,68}$ nickel, ${ }^{69}$ palladium, ${ }^{70}$ platinum, ${ }^{70 a, 71}$ copper,${ }^{72}$ silver,${ }^{73}$ gold, ${ }^{74}$ zinc, $^{75}$ cadmium, ${ }^{76}$ and mercury ${ }^{77}$ as metal centers. Among this plethora of transition metal complexes, chromium, ${ }^{78}$ rhenium, $^{79}$ ruthenium ${ }^{80}$ osmium, ${ }^{81}$ rhodium, ${ }^{82}$ iridium, ${ }^{83}$ palladium, ${ }^{84}$ platinum,${ }^{85}$ copper $^{86}$ silver,$^{87}$ zinc $^{88}$ cadmium, ${ }^{89}$ and mercury complexes ${ }^{90}$ have been reported to emit or absorb in the visible region. These photophysical properties render this class of organometallic complexes interesting for ion or organic molecule detection by selective binding of cation accompanied by a luminescent response, for electroluminescent material such organic light-emitting diodes (OLEDs) ${ }^{91}$ or lightemitting electrochemical diodes (LECS), ${ }^{92}$ for nuclear detection via plastic scintillators ${ }^{93}$ and finally for dye-sensitized solar cells (DSSCs) by using the absorption properties in the visible region.

\subsection{Ion and organic molecule detection}

Regarding the ion or organic molecule detection, two strategies can be considered, (i) the fluorescence (or phosphorescence) extinction when an ion binds or interacts with the emissive complex; and (ii) the generation or strong modification of fluorescence (or phosphorescence) when an ion binds or an organic molecule interacts with a non-emissive complex. The most representative examples are based on strategy (i). However, some dpa derivatives are known to be intrinsically fluorescent ${ }^{88 e-f, 94}$ and, as mentioned above, several transition metal complexes possess fluorescence properties.

As first example, a star-shaped ligand L16 (Figure 17) possessing a benzene core and 6 biphenyl-2,2'dipyridylamine substituents has been synthesized and studied in self-assembling on graphite surface. ${ }^{95}$ In the presence of a copper(II) salt, ligand L16 leads to a non-emissive 2D extended structure. The quenching of the fluorescence property of L16 (emission wavelength $\left(\lambda_{\mathrm{em}}\right)=409 \mathrm{~nm}$ in dichloromethane solution) was reached when a 1:2 ratio of $\mathbf{L} 16: \mathrm{Cu}^{\text {II }}$ was used. Unfortunately, no other cation has been studied to show selectivity for such extinction selectivity. 


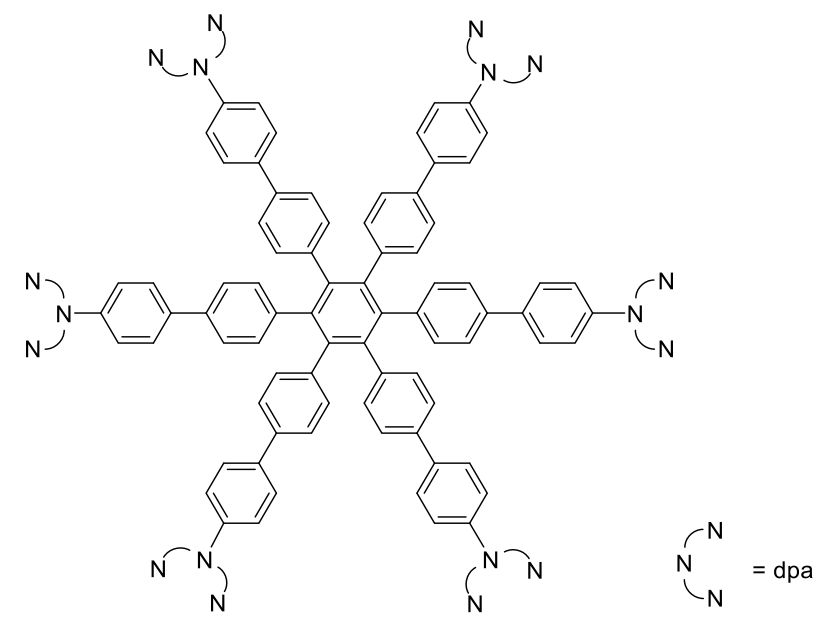

L16

Figure 17 Structure of the star-shaped ligand 16

Simpler structures having two to three dpa units (ligands L17-L20, Figure 18) and the corresponding copper(I) complexes have also been described (Figure 19). Various copper salts (Cul, $\mathrm{CuBr}$ and $\mathrm{CuCN}$ ) were investigated and, surprisingly, depending on the salt, various polymetallic structures were characterized. ${ }^{96}$ As copper(I) can coordinate two dpa ligands, organometallic polymers were formed adopting different conformations (trans, cis, inward-and outward-conformations), depending of the copper(I) precursor and the ligand/metal ratio (Figure 19).

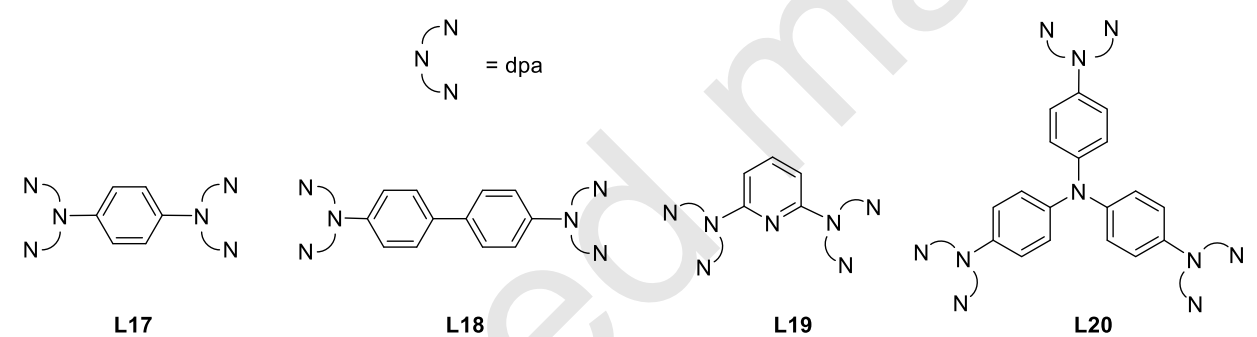

Figure 18 Structures of poly-dpa derivatives L17-L20

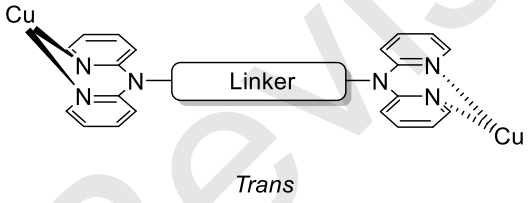

For complexes obtained with

$1: 3$ ratio of $\mathbf{L} \mathbf{1 8}$ :Cul

$1: 4$ ratio of $L 17: \mathrm{CuCN}$

$1: 4$ ratio of $L 19: \mathrm{CuBr}$

$1: 3$ ratio of LL19:Cul

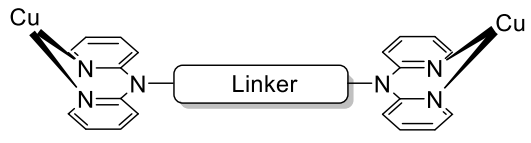

Cis

For complex obtained with $1: 3$ ratio of $\mathbf{L 2 0}: \mathrm{Cul}$

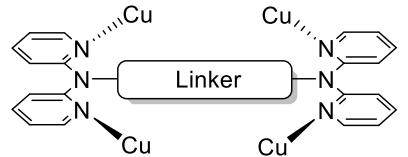

Inward

For complex obtained with

1:6 ratio of $\mathrm{L} 17: \mathrm{CuBr}$

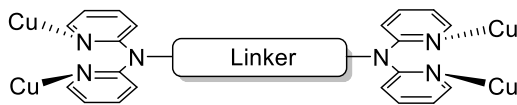

Outward

For complexes obtained with

1:4 ratio L18:CuCN

$1: 8$ ratio $\mathbf{L} 18: \mathrm{CuCN}$

Figure 19 Coordination modes of ligands L17-L20 
Notably, the two pyridine units were not always coordinated to the copper(I) metal center. In some cases, each pyridine bound a different metal center leading to a 2D Metal Organic Framework (MOF). Interestingly, a complete extinction of the blue fluorescence observed with the free ligand $\mathbf{L 1 7}\left(\lambda_{\mathrm{em}}=\right.$ $423 \mathrm{~nm}$ (main band) and $517 \mathrm{~nm}$ (shoulder) in dichloromethane solution) was observed with the organometallic polymer generated with ligand L17. The emission spectra of L17 in the presence of different concentration of copper(I) salt showed a drastic decrease of the fluorescence until a 1:6 ratio of L17:Cu(I). In this work, no selectivity in binding metal salts was reported. Such study was demonstrated with a second family of poly-dpa ligands, namely 1,2-, 1,3-, 1,4-(2,2'dipyridylaminomethyl)benzene ligands $\mathbf{L} \mathbf{2 1} \mathbf{L} \mathbf{2 2}$ and $\mathbf{L} \mathbf{2 4}, 2,6$-bis-(2,2'-dipyridylaminomethyl)pyridine L23 and 1,3,5-tris-(2',2"-dipyridylaminomethylbenzene $\mathbf{L 2 5}$ for bulk membrane transport (Figure 20). ${ }^{97}$ The coordination properties of these polydentate ligands were investigated with various silver(I) salts. The selectivity in binding metal ions depends on the nature of the fluxional core. Indeed, in the presence of a mixture of transition metal salts (Co(II), $\mathrm{Ni}(\mathrm{II}), \mathrm{Cu}(\mathrm{II}), \mathrm{Zn}(\mathrm{II}), \mathrm{Cd}(\mathrm{II}), \mathrm{Zn}(\mathrm{II}), \mathrm{Ag}(\mathrm{I})$ and $\mathrm{Pb}(\mathrm{II})), \mathrm{dpa}$ derivatives $\mathbf{L} \mathbf{2 2}-\mathbf{L} \mathbf{2 3}$ and $\mathbf{L} \mathbf{2 5}$ bind selectively the silver(I) cation. Unfortunately, no emission of the ligands or of the resulting silver(I) complexes have been reported.

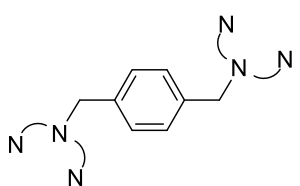

L21

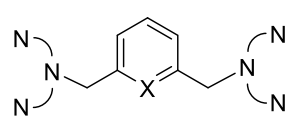

$X=C H$ L22
$X=N \quad$ L23

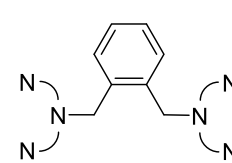

L24

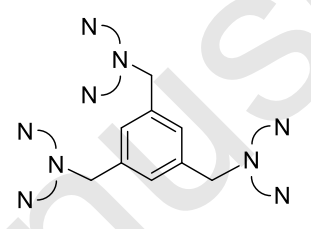

L25

Figure 20 Structures of poly-dpa derivatives L21-L25.

In 2000 , the coordination of $2,2^{\prime}, 2^{\prime \prime}$-tripyridylamine $\mathbf{L} \mathbf{2 6}$ and $2,2^{\prime}, \mathbf{3}^{\prime \prime}$-tripyridylamine $\mathbf{L} \mathbf{2 7}$ with various $\mathrm{Zn}(\mathrm{II})$ salts has been studied (Figure 21). ${ }^{98}$

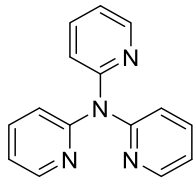

L26

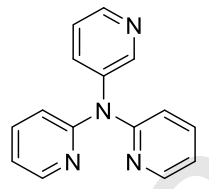

L27

Figure $\mathbf{2 1}$ Structures of ligands L26 and L27

The ligand $\mathbf{L 2 6}$ acted as a chelate with $\mathrm{ZnCl}_{2}$ (1 equivalent of L26) or $\mathrm{Zn}(\mathrm{OTf})_{2}$ (2 equivalents of L26) whereas only the 3-substituted pyridine moiety in ligand $\mathbf{L 2 7}$ bound $\mathrm{Zn}(\mathrm{OTf})_{2}$. The authors stated that the different mode of coordination (four ligand $\mathbf{2} \mathbf{2 7}$ mono coordinated to the zinc metal centre) was due to some steric hindrance. Interestingly, all the corresponding Zn(II) complexes exhibited a blue emission ( $\lambda_{\text {em }}$ between 422 to $432 \mathrm{~nm}$ ).

Later, the coordination behavior of the 2,2',3'-tripyridylamine ligand L27 has been studied with different silver(I) and zinc(II) metal salts. ${ }^{99}$ Various dinuclear complexes or $1 \mathrm{D}$ organometallic polymers were obtained with silver depending on the nature of the anion $\left(\mathrm{CF}_{3} \mathrm{CO}_{2}^{-}, \mathrm{TfO}^{-}, \mathrm{PF}_{6}{ }^{-}\right.$or $\left.\mathrm{ClO}_{4}{ }^{-}\right)$. Silver complexes are in a general manner di or tri-coordinated to two or three ligands L27. Unlike zinc which was able to bind 3-substituted pyridines, ligand $\mathbf{L 2 7}$ bind nonspecifically silver metal centre by the 2- or 3-substituted pyridine rings. The emissions of these silver complexes were observed between 366 to $368 \mathrm{~nm}$ in acetonitrile solution when ligand L27 was emitting at $361 \mathrm{~nm}$. The silver complexes exhibited also lower photoluminescent quantum yield $\left(\varphi_{\mathrm{em}}\right.$ between 0.16 to 0.18 for silver complexes vs. 0.38 for 
ligand L27). This property allowed the silver ion detection through the analysis of the decrease of the fluorescence intensity. Good correlation with the silver concentration (up to $4 \mathrm{mM}$ ) was obtained. Noteworthy, no decrease of fluorescence was observed in the presence of zinc(II) salts.

For organic molecule detection, Wang, Brown and co-workers reported the synthesis and photophysical properties of a zinc(II) complex in which the star-shaped ligand L28 held a 1,3,6-tris-(4'dpa)phenylbenzene core $\mathbf{L 2 8}$ (Figure 22)..$^{88 \mathrm{i}}$

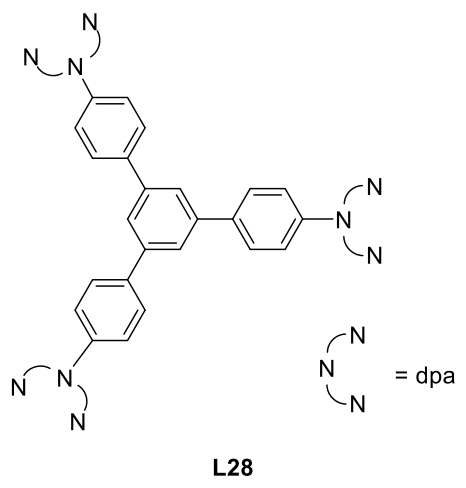

Figure 22 Structure of ligand $\mathbf{L 2 8}$

In the presence of three equivalents of $\mathrm{ZnCl}_{2}$, Ligand $\mathbf{L 2 8}$ led to the formation of the complex $\left[\left(\mathrm{ZnCl}_{2}\right)_{3}\right.$ L28]. This complex exhibited a broad fluorescence with an emission wavelenghth $\lambda_{\mathrm{em}}$ at $417 \mathrm{~nm}$ in solution and $432 \mathrm{~nm}$ in the solid state. Then, complex $\left[\left(\mathrm{ZnCl}_{2}\right)_{3} \mathrm{L28}\right]$ has been introduced in an optical sensor and twelve different solvents $(500 \mathrm{ppm})$ were selected to measure the decrease of the fluorescence intensity of the zinc(II) complex. As a result, benzene led to an important decrease of the fluorescence intensity whereas the structurally close solvents xylene and toluene almost did not alter its fluorescence intensity. Other protic polar solvents, alkanes or halogenated solvents did not modify the fluorescence. Based on crystallographic data, the affinity of benzene with $\left[\left(\mathrm{ZnCl}_{2}\right)_{3} \mathbf{L 2 8}\right]$ was observed through $\pi-\pi$ interactions between aromatic ring and the core of the ligand L28. These interactions might be responsible for the fluorescence quenching.

Finally, a dpa derivative based on guanosine has also been investigated for zinc salt detection. ${ }^{100}$ The fluorescence of the ligand $\mathbf{L 2 9}$ decreased upon addition of 6 equivalents of $\mathrm{Zn}\left(\mathrm{ClO}_{4}\right)_{2} \cdot 6 \mathrm{H}_{2} \mathrm{O}$ or $\mathrm{Zn}[(\mathrm{S})$ $\left.\mathrm{O}_{2} \mathrm{CCH}(\mathrm{Br}) \mathrm{CH}\left(\mathrm{CH}_{3}\right) \mathrm{CH}_{3}\right]_{2}$ without any shift of the emission wavelength, while a red-shift (from $403 \mathrm{~nm}$ to nearly $490 \mathrm{~nm}$ for $\lambda_{\mathrm{em}}$ ) and a decrease of the fluorescence intensity were observed with the analogous ligand L30. This double effect rendered the detection of the zinc(II) salt easier (Figure 23).

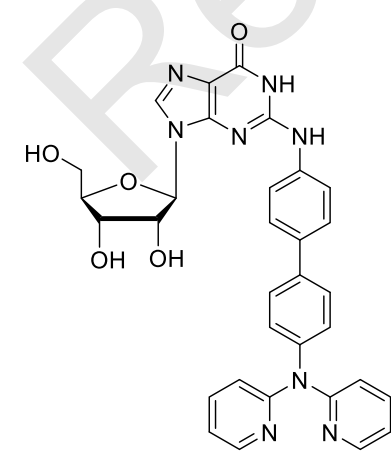

L29

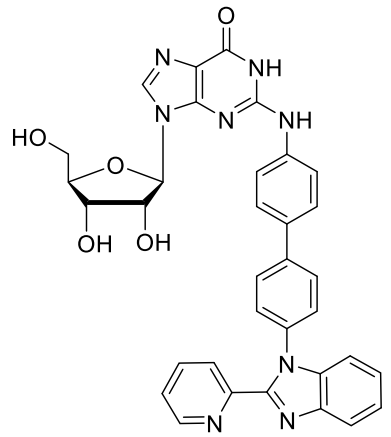

L30

Figure $\mathbf{2 3}$ Structure of guanosine chelate $\mathbf{L 2 9}$ and $\mathbf{L 3 0}$ 


\subsection{Electro and photoluminescent materials}

Fluorescent or phosphorescent transition metal complexes can also find applications in electroluminescent materials such as OLED ${ }^{91}$ and LEC. ${ }^{92}$ Both devices are dedicated for light applications and the most important difference is that LEC devices are specific of ionic transition metal complexes which lead to simpler architecture device as no injection and transport electron or hole layers are required.

In 2010, Huo et al. synthesized dpa-based ligands L31 and L32 bearing either a phenyl or a (2',4'difluorophenyl) substituent and the corresponding cyclometallated platinum complexes C55-C56 (Figure 24). ${ }^{101}$

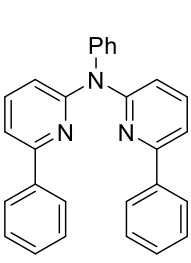

L31

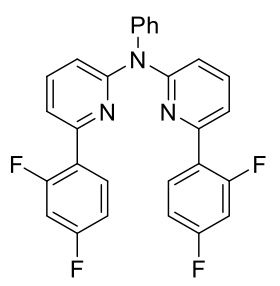

L32

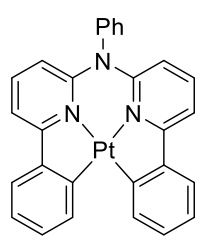

C55

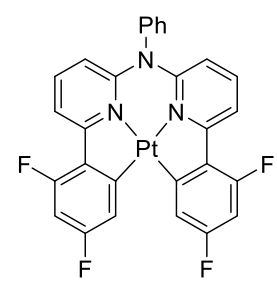

C56

Figure 24 Structure of ligands L31 and L32 and platinum(II) complexes C55 and C56

The phosphorescent emissions of such platinum complexes have been assigned by the author to an admixture of intraligand charge transfer (ILCT) and metal to ligand charge transfer (MLCT). The C55 complex exhibited a high quantum yield of 0.74 with two maxima for the emission wavelengths at 512 and $548 \mathrm{~nm}$ (in 2-methyltetrahydrofuran solution). Due to its highly emissive properties $\left(\varphi_{\mathrm{em}}\right)$, complex C55 has been investigated in OLED technology with an optimized device configuration consisting in ITO/CFx/NBP/TCTA/(TPBI + 30 wt \% TCTA) + 4 wt \% C55/TPBi/Alq/Mg:Ag (ITO: indium tin oxide; CF $_{x}$, NPB: 4,4'-bis[N-(1-naphthyl)- $N$-phenylamino]biphenyl; TCTA: 4,4',4"'-tris(N-carbazolyl)-triphenylamine; TPBi: 1,3,5-tris $\left(N\right.$-phenylbenzimidazol-2-yl)benzene). The best device showed bright green emission $\left(\lambda_{\mathrm{em}} / \mathrm{CIE}\right.$ coordinates $(x, y): 512 \mathrm{~nm} / 0.318,0.622$ ) with external quantum efficiency (EQE) of $14.7 \%$ and current efficiency of $50.0 \mathrm{Cd} . \mathrm{A}^{-1}$ at a current density of $0.01 \mathrm{~mA} . \mathrm{cm}^{-2}$. The highest luminance $L$ of $3698 \mathrm{Cd} . \mathrm{m}^{-2}$ was observed at a current density of $10 \mathrm{~mA} \cdot \mathrm{m}^{-2}$ (at $8.64 \mathrm{~V}$ ) but also led to a decrease of the EQE to 10.6 $\%$.

In direct line with the previous study, the unsymmetrical dpa derivatives L33-L35 were prepared and the corresponding platinum(II) complexes evaluated in the preparation of new OLED devices (Figure 25). ${ }^{102}$ 


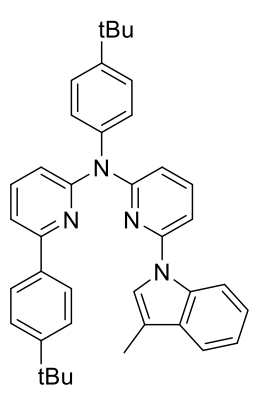

L33

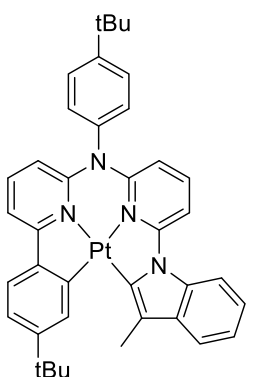

C57

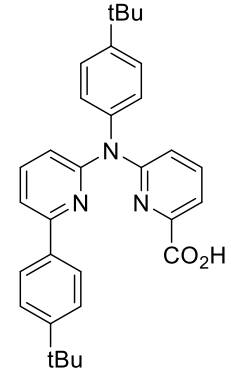

L34

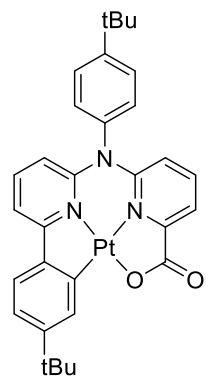

C58

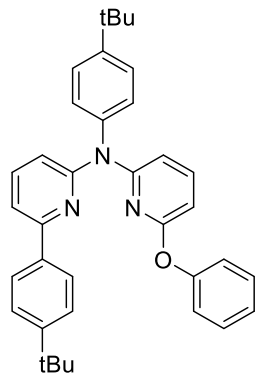

L35

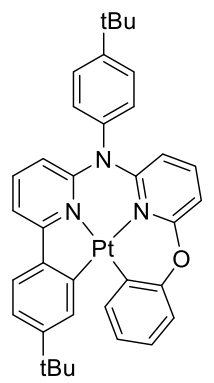

C59

Figure 25 Structure of ligands L33-L35 and platinum(II) complexes C57-C59

The three platinum(II) complexes C57-C59 (Figure 25) were green emitters with $\lambda_{\text {em }}$ ranging from 504 to $513 \mathrm{~nm}$ with a shoulder centered approximatively at $535 \mathrm{~nm}$ (in degassed dichloromethane). Complexes with ligands L33 and L34 exhibited photoluminescent quantum yields of 0.27, when C59 complex displayed a quantum yield of 0.47 (in degassed dichloromethane relative to $f a c$ - $\left[\operatorname{Ir}(\mathrm{ppy})_{3}\right], \varphi_{\mathrm{em}}=0.4$ ). The OLED devices possessed the following architecture ITO/HAT-CN/TAPC/TCTA/mCP: Pt(II) (10 wt $\%$ )/TmPyPB/Liq/Al (HAT-CN: 1,4,5,8,9,11-hexaazatriphenylene-hexacarbonitrile; TAPC: 1,1-[4-[N,N-di( $p$ tolyl)-amino]phenyl]cyclohexane; mCP: 1,3-bis(N-carbazolyl)benzene; TmPyPB: 1,3,5-tri[3-pyridyl)phen-3-yl]benzene; Liq: 8-hydroxyquinolinolato lithium). The emissions of the devices were slightly redshifted compared to the emissions in solution. Indeed, C57 emitted greenish yellow light $\left(\lambda_{\mathrm{em}} / \mathrm{CEI}\right.$ coordinates $(x, y): 548 \mathrm{~nm} / 0.44,0.53$ ) with EQE of $11.8 \%$, current efficiency of $38.8 \mathrm{Cd}^{-\mathrm{A}^{-1}}$ and power efficiency of $20.2 \mathrm{Im} . \mathrm{W}^{-1}$ at brightness of $1000 \mathrm{Cd} . \mathrm{m}^{-1}$. C58 and C59 complexes showed yellowish-green emission ( $\lambda_{\text {em }} /$ CEI coordinates $(x, y): 540 \mathrm{~nm}$ for both complexes/0.36,0.58 and $0.32,0.61$, respectively) with EQE of 11.5 and 11.9 , current efficiency of 38.5 and $42.4 \mathrm{Cd} . \mathrm{A}^{-1}$, and power efficiency of 23.7 and $29.420 .2 \mathrm{Im} . \mathrm{W}^{-1}$ at brightness of $1000 \mathrm{Cd} . \mathrm{m}^{-1}$, respectively.

The ligand L36 having 6,6'-trifluoromethylpyrazolyl substituent has been coordinated to an osmium(II) metal center associated with phosphine ligands (Figure 26). ${ }^{103}$ The two synthesized complexes $\left[\mathrm{Os}(\mathrm{L36})\left(\mathrm{PMePh}_{2}\right)_{2}\right]$ and $\left[\mathrm{Os}(\mathrm{L36})\left(\mathrm{PMe}_{2} \mathrm{Ph}\right)_{2}\right]$ exhibited strong red emission at $\lambda_{\mathrm{em}} 628$ and $634 \mathrm{~nm}$ with $\varphi_{\mathrm{em}}$ of 0.40 and 0.27 (in degassed dichloromethane), respectively. Due to these strong deep red emissions of complexes $\left[\mathrm{Os}(\mathbf{L 3 6})\left(\mathrm{PMePh}_{2}\right)_{2}\right]$ and $\left[\mathrm{Os}(\mathbf{L} 36)\left(\mathrm{PMe}_{2} \mathrm{Ph}\right)_{2}\right]$, organic light emitting diodes (OLEDs) have been prepared with the following architecture ITO/NPB/TCTA/TPBi: $\left[\mathrm{Os}(\mathrm{L36})\left(\mathrm{PMePh}_{2}\right)_{2}\right]$ or [Os(L36)(PMe $\left.2 \mathrm{Ph})_{2}\right]$ (4 vol\%)/TPBi/LiF/Al (NPB: 4,4'-bis[ $N$-(1-naphthyl)- $N$-phenylamino]biphenyl; TCTA: 4,4',4"'-tris(N-carbazolyl)-triphenylamine; TPBi: 1,3,5-tris( $N$-phenylbenzimidazol-2-yl)benzene). Additionally, to the devices prepared with complexes $\left[\mathrm{Os}(\mathrm{L36})\left(\mathrm{PMePh}_{2}\right)_{2}\right] \mathbf{C 6 0}$ and $\left[\mathrm{Os}(\mathrm{L36})\left(\mathrm{PMe} \mathrm{P}_{2} \mathrm{Ph}\right)_{2}\right]$ C61, a device doped with [Ir(piq) ${ }_{3}$ ] was prepared for comparison (piq: phenyl isoquinoline). All devices prepared with [Ir(piq) $\left.{ }_{3}\right], \mathbf{C 6 0}$ and $\mathbf{C 6 1}$ exhibited a deep red emission with CIE coordinates at $(0.67,0.33)$, 
$(0.63,0.36)$ and $(0.65,0.35)$ with current density of $5 \mathrm{~mA} . \mathrm{cm}^{-2}$, respectively. Both devices prepared with complexes $\mathbf{C 6 0}$ and $\mathbf{C 6 1}$ showed better performance than the device with $\left[\operatorname{Ir}(\mathrm{piq})_{3}\right]$ as phosphorescent dopant. The highest current efficiency of $14.0 \mathrm{Cd} . \mathrm{A}^{-1}$ at $5 \mathrm{~mA} . \mathrm{cm}^{-2}$ and best EQE of $9.8 \%$ were observed with the device prepared with complex C60. However, the devices prepared with Os(II) complexes required higher operation voltage than with $\operatorname{Ir}$ (III) complex due to the shallow HOMO level of Os(II) which may induce a large carrier injection barrier and charge trap.
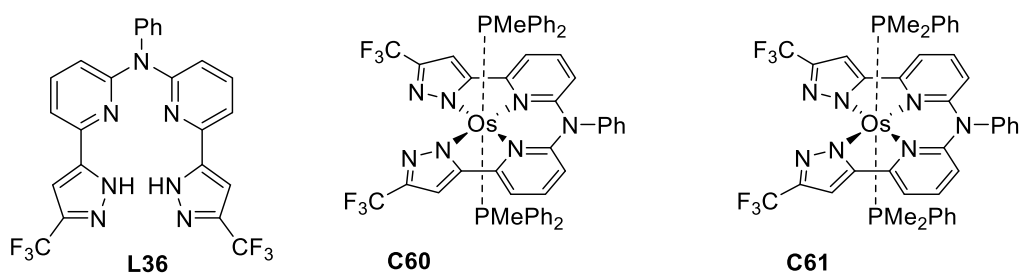

Figure 26 structure of ligand L36 and osmium(II) complexes [Os(L36)(PMePh $\left.)_{2}\right] \mathbf{C 6 0}$ and $\left[\mathrm{Os}(\mathrm{L36})\left(\mathrm{PMe} \mathrm{P}_{2} \mathrm{Ph}\right)_{2}\right] \mathbf{C 6 1}$

The tridentate extended dpa derivatives L37 incorporating an additional 2-pyridylamino framework on the dpa motif has been extensively studied by the group of Heinze and the properties of the corresponding complexes have been compared with their analogous complexes bearing the tripyridine ligand L38 (Figure 27). ${ }^{78 c, 104}$<smiles>CN(c1ccccn1)c1ccccn1</smiles>

L37<smiles>Nc1cc(-c2ccccn2)nc(-c2ccccn2)c1</smiles>

L38

Figure 27 Structures of tridendate ligands L37-L38

Among these complexes, the photoluminescent ruthenium(II) complexes $\mathbf{C 6 2 - C 6 4}$, bearing either $\mathbf{L 3 7}$ or L38 ligand in combination with an ester-substituted terpyridine ligand, have been studied in light emitting electrochemical cell (LEC) technology (Figure 28). ${ }^{105}$

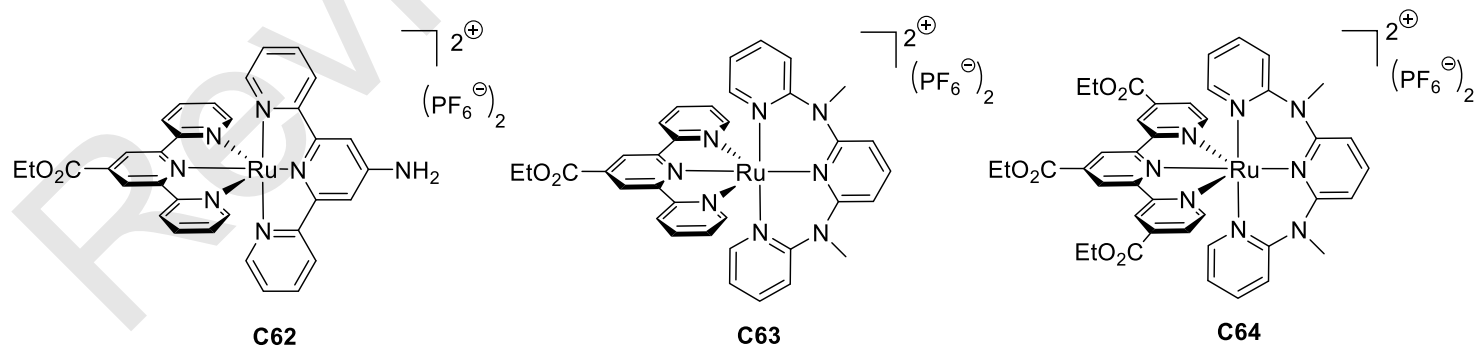

Figure 28 Structure of ruthenium(II) complexes C62-C64

The configuration of the material was based on the following structure ITO/PEDOT:PSS/ruthenium(II) complex/Ag (PEDOT: poly(3,4-ethylenedioxythiophene); PSS: poly(styrenesulfonate). Different devices have been prepared with or without 20 wt\% PMMA (poly(methylmethacrylate) as additive with complexes $\mathbf{C 6 2}$ or $\mathbf{C 6 3}$ as phosphorescent dopant of the emissive layer. At low voltage (3V), only the device incorporating complex $\mathbf{C 6 3}$ without PMMA emitted in the red region $\left(\lambda_{\mathrm{em}}\right.$; CIE coordinates $(x, y)$ : 
$731 \mathrm{~nm} ; 0.725,0.275)$. At higher voltage (up to $6 \mathrm{~V}$ ), the devices with PMMA as additive and incorporating the Ru(II) complexes C62-C63 emitted in the red to near infra-red $\left(\lambda_{\text {em }} / \mathrm{CIE}\right.$ coordinates $(x, y): 733$ $\mathrm{nm} / 0.709-0.291$ for C62at 4V; $722 \mathrm{~nm} / 0.717-0.283$ for C63 at $6 \mathrm{~V} ; 745 \mathrm{~nm} / 0.729 / 0.271$ for C64 at 5V). The authors stated that these tridentate ligand-ruthenium complexes containing devices were the LECs possessing the longest emission wavelength. Regarding the highest performances of these LECs devices, luminance $(L)$ and external quantum efficiency $(E Q E)$ were obtained with the device incorporating complex $\mathrm{C} 63$ at a voltage of $6 \mathrm{~V}$ and was measured at $3.4 \mathrm{~cd} . \mathrm{m}^{-2}$ and $0.028 \%$.

Photoluminescent cationic copper(I) complexes bearing dpa ligand $\mathbf{L} \mathbf{1}$ in association with $\mathrm{N}$-heterocyclic carbenes (NHC) ${ }^{86}$ have also been studied in LEC technology. The cationic copper(I) complex $\mathbf{C 6 5}$ (Figure 29) exhibited a bright and blue emission with $\lambda_{\mathrm{em}}$ at $463 \mathrm{~nm}$.

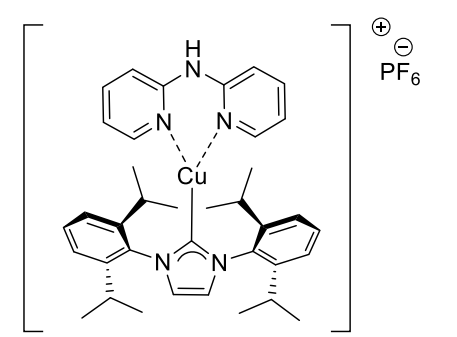

C65

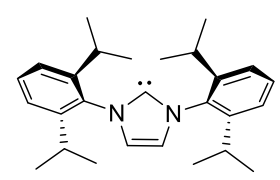

$\mathrm{IPr}$

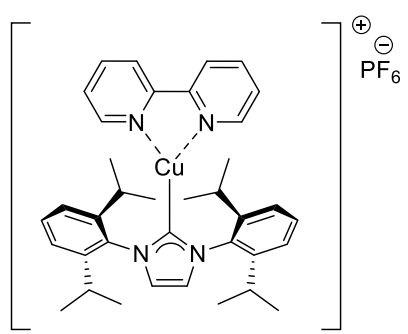

C66

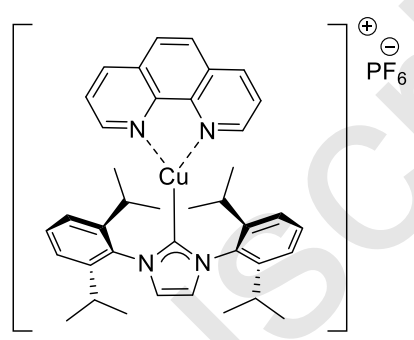

C67

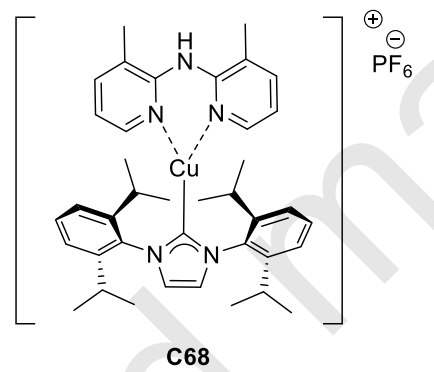

Figure 29 Structures of complexes C65-C68

The $\lambda_{\mathrm{em}}$ was ascribed to a MLCT and presented a large Stokes shift. The analog complexes $[\mathrm{Cu}(\mathrm{bpy})(\mathrm{IPr})]\left[\mathrm{PF}_{6}\right](\mathrm{C66})^{86}$ or $\left[\mathrm{Cu}\left(\right.\right.$ phen)(IPr)][OTf] $(\mathrm{C67})^{106}$ (Figure 29) both exhibited a weak and redshifted $\lambda_{\mathrm{em}}$ around $650 \mathrm{~nm}$. This important difference in the $\lambda_{\mathrm{em}}$ is due to the strong electron donating property of the central nitrogen atom in dpa ligand. Indeed, the DRX analyses of these different copper(I) complexes showed that the dpa ligand is planar in a general manner indicating that the $p$ orbital of the nitrogen atom is parallel to the $p$ orbital of the pyridine ring thus allowing delocalization of the electrons in the pyridine rings. This structural observation was also confirmed by DFT and TD-DFT calculations. ${ }^{107}$ DFT calculations have also shown that the HOMO of complex $\mathbf{C 6 5}$ was located on the metal center and the LUMO mainly located on the dpa ligand. In this complex, the $\lambda_{\mathrm{em}}$ is ruled by the nitrogen ligand, unlike the bipyridine or phenanthroline complexes. The introduction of electron withdrawing groups, stabilizing the LUMO, generated a red shift of the $\lambda_{\mathrm{em}}$ whereas electron donor groups, destabilizing the LUMO, generated a blue shift of the $\lambda_{\mathrm{em}}$. Taking advantage of the blue luminescence of the family of (NHC)copper(I) complexes bearing 2,2'-dipyridylamine ligands, one of the brightest complexes having photoluminescent quantum yield $\left(\varphi_{\mathrm{em}}\right)$ up to 0.86 has been applied in the fabrication of light emitting electrochemical cells (LECS). ${ }^{108}$ Devices obtained with complex $\mathbf{6 8 8}$ were the first LEC incorporating cationic copper complexes having blue emission (with CIE coordinate of $0.23 / 0.28$ ) showing figure of 
merit similar to those obtained for LECs incorporating iridium complexes, at that time. Nevertheless, their lifetime $t_{1 / 2}$ were short with best value of $16.5 \mathrm{~min}$.

In the context of nuclear detection with plastic scintillator, ${ }^{109}$ dpa ligands have also been used as ancillary ligands for cationic cyclometallated iridium(III) complexes (cyclometallating ligands $=2$-phenylpyridine, ppy; $N$-phenylpyrazine, ppz; benzoquinoline, bzq or phenylisoquinoline, piq) (Figure 30). ${ }^{110}$ The photophysical properties of the corresponding complexes have been studied and compared to those of complexes incorporating a bipyridine $\mathbf{L} \mathbf{2}$ or phenanthroline $\mathbf{L} \mathbf{3}$ ligand.

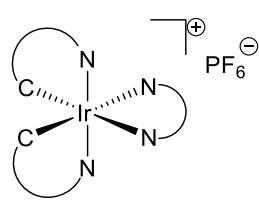

$\mathrm{N}^{\wedge} \mathrm{N}=$ dpa (L1), bipy (L2) or phen $(\mathbf{L} 3)$

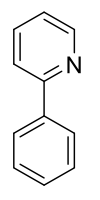

ppy

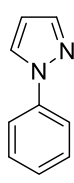

$\mathrm{ppz}$

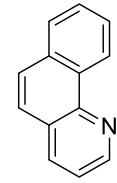

bzq

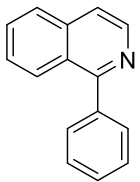

piq

Figure 30 General structure of cationic cyclometallated iridium(III) complexes with $\mathrm{N}^{\wedge} \mathrm{N}$ ancillary ligands.

Considering the absorption spectra, the profile appeared to be mainly driven by the cyclometallating ligand. Nevertheless, replacing bipyridine $\mathbf{L} \mathbf{2}$ or phenantroline $\mathbf{L} \mathbf{3}$ ligands by dpa $\mathbf{L} \mathbf{1}$ led in most cases to a blue shift of the $\lambda_{\text {em }}$ originating from a MLCT. Some of these cationic iridium(III) complexes have been selected as dopant for the preparation of plastics. Due to solubility issue of these complexes in the styrene matrix, samples were prepared with concentration below or equal to $0.05 \mathrm{wt} \%$. Among the plastics obtained, those incorporating dpa-iridium complexes exhibited emission resulting only from the styrene matrix due to the low $\varphi_{\mathrm{em}}$ of the dopant. Best results of radio- and photoluminescence were here obtained with plastic incorporating bipyridine or phenanthroline iridium(III) complexes and showed scintillation yields between 400 to 1500 ph. $\mathrm{MeV}^{-1}$.

\subsection{Application in Dye-Sensitized Solar Cells}

Dipyridylamine metal complexes have been also studied as catalysts in photoredox chemistry thanks to their photophysical properties, and more specifically their absorption in the visible region, ${ }^{57}$ but also in material science and more particularly as component for dye-sensitized solar cells (DSSCs). To the best of our knowledge, the first example was reported in 2009 by Masuda and co-workers. ${ }^{111}$ The dpa derivative L39 was used as ancillary ligand of a ruthenium(II) complex C69. Both the tert-butyl and methoxy substituent on the $\mathrm{N}$-phenyl-2,2'-dipyridylamine modified the HOMO and LUMO energy level and increased the lifetime performance of the device (Figure 31).<smiles>COc1ccc(N(c2cc(C(C)(C)C)ccn2)c2cc(C(C)(C)C)ccn2)cc1</smiles>

L39

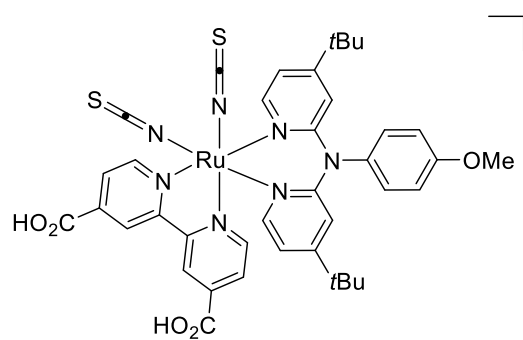

669

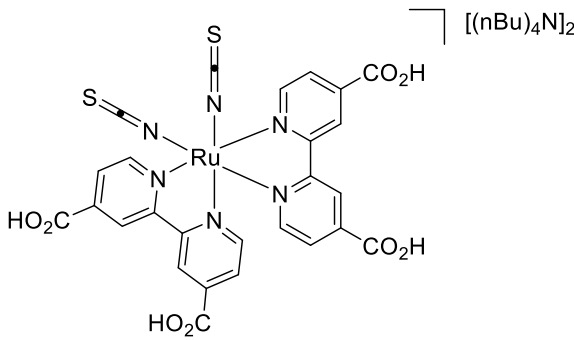

C70 "N719"

Figure 31 Structure of ligand L39 and complex C69-C70. 
The absorption spectrum of complex $\mathbf{C 6 9}$ showed two bands centered at $381 \mathrm{~nm}$ (molar extinction coefficient $\left.(\varepsilon)=14.7 \times 10^{3} \mathrm{M}^{-1} \mathrm{~cm}^{-1}\right)$ and $514 \mathrm{~nm}\left(\varepsilon=49.4 \times 10^{3} \mathrm{M}^{-1} \mathrm{~cm}^{-1}\right)$ which are assigned to MLCT bands. The ionization potential $\left(\mathrm{E}_{\mathrm{ox}}\right)$ was measured at $-5.1 \mathrm{eV}$, which is $0.3 \mathrm{eV}$ more negative than the one of $\mathrm{I}_{2} / \mathrm{I}_{3}$. The excited-state ionization potential ( $\mathrm{E}_{\text {ox }}^{*}$ or $\mathrm{E}^{*}{ }_{\text {LUMO) }}$ of $\mathrm{C} 69$, obtained from zero-zero excitation energy $\left(E_{0-0}\right)$, was approximated at $-3.3 \mathrm{eV}$, which is $0.6 \mathrm{eV}$ more positive than the $\mathrm{TiO}_{2}$ conduction band. Devices were prepared with complex $\mathbf{C 6 9}$ and the so-called $\mathrm{N} 719$ complex $\mathbf{C 7 0}$ ( $\mathrm{E}_{\mathrm{ox}}=-$ $6.01 \mathrm{eV}$ and $\left.\mathrm{E}^{*}{ }_{\mathrm{ox}}=-3.64 \mathrm{eV}\right) .{ }^{112}$ The device prepared with $\mathbf{6 6 9}$ led to a short circuit current density $\left(J_{s c}\right)$ of $17.3 \mathrm{~mA} . \mathrm{cm}^{-2}$, an open-circuit photo-voltage $\left(V_{o c}\right)$ of $640 \mathrm{mV}$ and a fill factor $(F F)$ of 0.65 , giving an overall conversion efficiency $(\eta)$ of $7.2 \%$. Interestingly, these performances were slightly lower than the one observed under the same conditions with the ruthenium complex $\mathbf{C 7 0}$.

The group of Kim modified the dipyridylamine ligand by replacing the $\mathrm{N}$-para-methoxy phenyl substituent by an aliphatic chain and the $t$ Bu groups of the dpa skeleton by a (hetero)aryl conjugated framework (ligands L40 and L41, Figure 32). ${ }^{113}$ The corresponding complexes $\mathbf{C 7 1}$ and C72, analogs of C69, have been prepared and studied in solar cell devices.

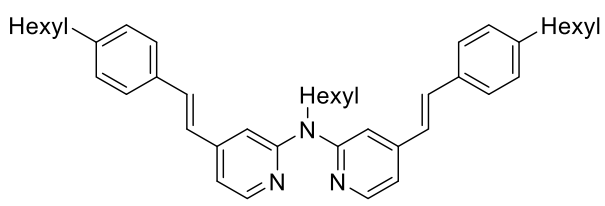

L40

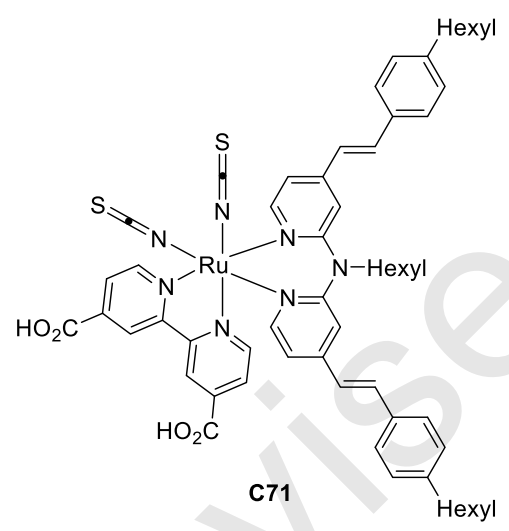

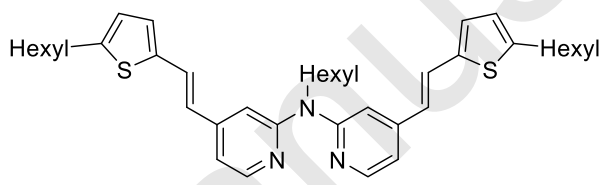

L41

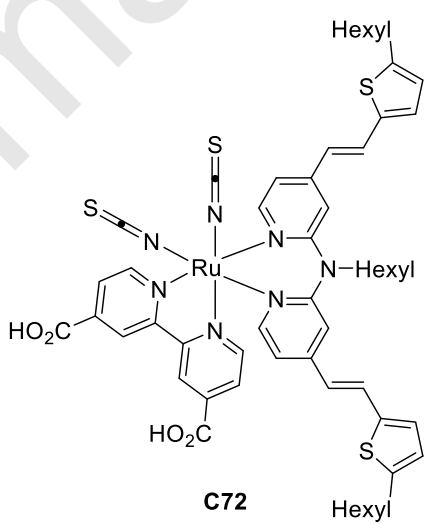

Figure 32 Structure of ligands $\mathbf{L} 40$ and $\mathbf{L 4 1}$, and ruthenium complexes $\mathbf{C 7 1}$ and $\mathbf{C 7 2}$.

Absorption properties of complexes $\mathbf{C 7 1}$ and $\mathbf{C 7 2}$ were as follows, maxima absorption wavelengths $\left(\lambda_{\text {abs }}\right)$ of $418 \mathrm{~nm}\left(\varepsilon=16.9 \times 10^{3} \mathrm{M}^{-1} \mathrm{~cm}^{-1}\right)$ and $531 \mathrm{~nm}\left(\varepsilon=10.9 \times 10^{3} \mathrm{M}^{-1} \mathrm{~cm}^{-1}\right)$ for $\mathrm{C71}$ and $420 \mathrm{~nm}(\varepsilon=24.4 \times$ $\left.10^{3} \mathrm{M}^{-1} \mathrm{~cm}-1\right)$ and $531\left(\varepsilon=15.4 \times 10^{3} \mathrm{M}^{-1} \mathrm{~cm}^{-1}\right)$ for $\mathbf{C 7 2}$. Of note, the molar extinction coefficient of $\mathbf{C 7 2}$ was higher than that of $\mathbf{C 7 0}\left(\varepsilon=14.9 \times 10^{3} \mathrm{M}^{-1} \mathrm{~cm}^{-1}\right.$ at $\lambda_{\text {abs }}=380 \mathrm{~nm}$ and $\varepsilon=14.4 \times 10^{3} \mathrm{M}^{-1} \mathrm{~cm}^{-1}$ at $\lambda_{\text {abs }}=$ $520 \mathrm{~nm}$ ). The $\mathrm{E}_{\mathrm{ox}}$ of $\mathbf{C 7 1}$ and $\mathbf{C 7 2}$ were measured at 0.95 and $0.92 \mathrm{~V}$ vs. NHE (-3.49 and $3.52 \mathrm{eV}$ vacuum scale)) and $E^{*}$ ox approximated at -1.00 and $-0.96 \mathrm{~V}$ vs. NHE (-5.44 and $5.40 \mathrm{eV}$ vacuum scale), respectively. Solar cells devices with $\mathbf{C 7 1}$ and $\mathbf{C 7 2}$ were prepared and compared with device using N719.

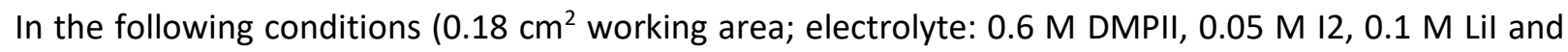
tert-butylpyridine in acetonitrile), the performances were $J_{s c}$ of 17.1 and $18.89 \mathrm{~mA} . \mathrm{cm}^{-2}, V_{o c}$ of $660 \mathrm{mV}$ (in both case), and $F F$ of 0.69 (in both case), corresponding to $\eta$ of 7.90 and $8.76 \%$, respectively. Of note, 
the device prepared with $\mathbf{C 7 2}$ exhibited higher performance parameter that the one prepared with $\mathbf{C 7 0}$ ( $\eta$ of 8.76 vs. $8.19 \%$ for $\mathbf{C 7 2}$ vs $\mathbf{C 7 0}$ ) and was attributed to the higher $\varepsilon$ of $\mathbf{C 7 2}$ compared to $\mathbf{C 7 0}$.

Ruthenium complexes C73-C75 containing ligands L37 (Figure 27) and L42, represented in Figure 33, are related to the above-mentioned complexes C62-C64 (Figure 28). Their deep-red emissions allowed some studies in lighting devices, ${ }^{105}$ and their absorption properties in the UV and visible regions fitted with DSSCs applications. ${ }^{114}$

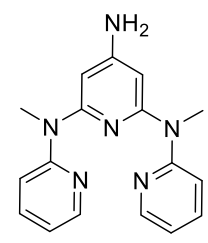

L42

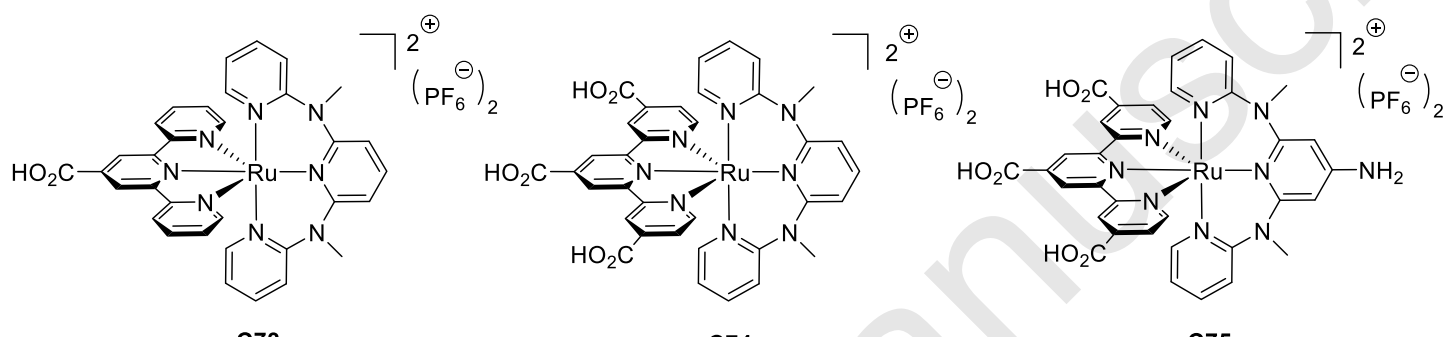

C73

C74

C75

Figure 33 Structures of ligands L42 and Ruthenium(II) complexes C73-C75

Indeed, complexes C73-C75 showed several maxima absorption wavelengths assigned to MLCT bands in the visible region between 472 and $680 \mathrm{~nm}$. Nevertheless, the $\varepsilon$ calculated for these complexes were at least three-fold lower than that of $\mathbf{C 7 0}$. Even if photostability was more important for complexes C73C75 compared to N719 complex C70, the performance parameters of DSSCs with complexes C73-C75 as dyes were twenty-fold lower than those of device prepared with C70 ( $\eta=5.0 \%$ for N719 vs. $\eta=0.26 \%$ for complex $\mathbf{C 6 3}$ for example). These poor DSSCs performances were attributed to electron recombination with the oxidized electrolyte $\left(\mathrm{I}_{3}^{-}\right)$at the $\mathrm{TiO}_{2}$ electrode. The positive charge on the ruthenium(II) complexes might attract the negatively charged $\mathrm{I}_{3}{ }^{-}$near the $\mathrm{TiO}_{2}$ surface and consequently might provoke undesired back electron transfer. To tackle this issue, positively charge $\mathrm{Co}^{3+} / \mathrm{Co}^{2+}$ couples, $\left[\mathrm{Co}(\text { bipy })_{3}\right]^{2+/ 3+}$ and $\mathbf{C 7 6}$, were envisaged to replace the negatively redox mediator $\mathrm{I}_{3}-\mathrm{I}_{2} \cdot{ }^{115} \mathrm{Using}$ complex C74 as dye, several DSSCs were prepared with electrolytes involving [Co(bipy $\left.)_{3}\right]^{2+/ 3+}$ or $\mathbf{C 7 6}$ as positively charged redox mediator and the $\mathrm{I}_{3}{ }^{-} / \mathrm{I}_{2}$ for comparison (Figure 34 ).

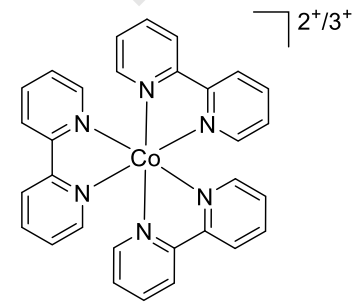

$\left[\mathrm{Co}(\text { bipy })_{3}\right]^{2+/ 3+}$

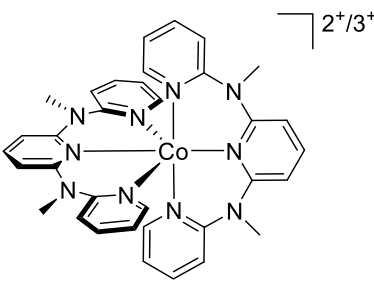

C76

Figure 34 Structures of $\mathrm{Co}^{2+} / \mathrm{Co}^{3+}$ redox mediators $\left[\mathrm{Co}(\text { bipy })_{3}\right]^{2+/ 3+}$ and $\mathrm{C76}$ 
DSSCs prepared with $\left[\mathrm{Co}(\text { bipy })_{3}\right]^{2+/ 3+}$ showed lower efficiency than devices using $\mathrm{I}_{3}{ }^{-} / \mathrm{I}_{2}$ as redox mediator, the one elaborated with $\mathbf{C 7 6}$ increased both $I_{s c}$ and $V_{o c}$ and led to an efficiency two-fold higher. To explain the different results with the $\left[\mathrm{Co}(\text { bipy })_{3}\right]^{2+/ 3+}$ and $\mathbf{C 7 6}$ redox mediators, the authors proposed that the efficiency was correlated to the $\pi^{*}$ orbitals energy levels which were higher in the case of the electron rich ligand L39 than with bipyridine ligand. Importantly, the enhancement of the DSSC efficiency using C76 as redox mediator depended on the dye as shown later by the same group using another ruthenium(II) complex as dye and for which $\mathrm{I}_{3}{ }^{-} / \mathrm{I}_{2}$ was found better than $\mathbf{C 7 6} .^{116}$

\section{Conclusion}

2,2'-Dipyridyliamine and 2,2-dipyridyliamine-based metal complexes have been implemented with success in a number of catalytic processes and light-emitting materials and devices. In this review, we have demonstrated that these ligands sometimes lead to improved performances when compared to the ubiquitous 2,2'-bipyridine-based organometallic complexes. One major difference between these two family of ligands is found in the formation of metallacycles with 5- or 6-members, but may be more importantly, the bridging nitrogen atoms in dpa is a direct and easily accessible manifold to modulate the electronic and steric properties of dpa-based ligands. Furthermore, the nitrogen atom is also an anchorage point for supported catalysis of for the design of task specific ligands. Last but not least, the presence of a bridging $\mathrm{N}-\mathrm{H}$ group at the proximity of a catalytic centre may play a crucial role for substrate orientation/activation and product release through $\mathrm{H}$-bonding. Altogether, these properties make dpa a ligand of high potential which should be considered and utilized with the same attention and interest as other well-stablished $N, N$-chelates. It is likely that the future years will see an increasing interest for this so far neglected ligands.

\section{References}

\footnotetext{
1 a) A. P. Smith and C. L. Fraser, Compr. Coord. Chem. II, 2004, 1, 1; b) O. Maury and H. Le Bozec, Acc. Chem. Res., 2005, 38, 691; c) V. Balzani, G. Bergamini, F. Marchioni and P. Ceroni, Coord. Chem. Rev., 2006, 250, 124; d) H.-L. Kwong, H.-L. Yeung, C.-T. Yeung, W.-S. Lee, C.-S. Lee and W.-L. Wong, Coord. Chem. Rev., 2007, 251, 2188;

2 a) G. Van Koeten and K. Vrieze, Adv. Organomet. Chem., 1982, 21, 151; b) B. L. Small, Acc. Chem. Res., 2015, 48, 2599 ; c) L. Guo, S. Shengyu, X. Sui and C. Chen, ACS Catal., 2016, 6, 428; d) C. Zhou, M. Brookhart, Acc. Chem. Res., 2018, 51, 1831;

${ }^{3}$ a) S. Dagorne, S. Bellemin-Laponnaz and A. Maisse-François, Eur. J. Inorg. Chem. 2007, 913; b) G. Desimoni, G. Faita and K. A. Jorgensen, Chem. Rev. ,2011, 111, PR284; c) A. Pfaltz, Asymmetric Synthesis (2 ${ }^{\text {nd }}$ Edition), 2008, 139, Wiley-VCH, Weinheim;

${ }^{4}$ a) L. Bourget-Merle, M. F. Lappert and J. R. Severn, Chem. Rev., 2002, 102, 3031; b) C. Camp and J. Arnold, Dalton Trans., 2016, 45, 14462.

${ }^{5}$ A. E. Chichibabin and O. A. Zeide, J. Russ. Chem. Soc. 1914, 46, 1216.

For other early synthetic methods, see (a) E. Steinhäuser and E. Diepolder, E. J. Prakt. Chem. 1916, 93, 387; (b) F. Tjosaas and A. Fiksdahl, J. Organomet. Chem. 2007, 692, 5429.

6 a) D. W. Brogden and J. F. Berry, Comments Inorg. Chem., 2016, 36, 17.

7 a) J. F. Hartwig, Angew. Chem. Int. Ed., 1998, 37, 2046; b) J. P. Wolfe, S. Wagaw, J.-F. Marcoux and S. L. Buchwald; Acc. Chem. Res., 1998, 31, 808; c) D. S. Surry, S. L. Buchwald, Chem. Sci., 2011, 2, 27; d) Y. Aubin, C. Fischmeister, C. M. Thomas, J.-L. Renaud, Chem.Soc.Rev., 2010, 39, 4130.

8 a) P. N. R. Vennestrom, C. M. Osmundsen, C. H. Christensen and E. Taarning, Angew. Chem. Int. Ed., 2011, 50, 10502; b) P. J. Deuss, K. Barta and J. G. de Vries, Catal. Sci. Technol., 2014, 4, 1174; c) M. J. Clement, A. Corma, S. Iborra, Green Chem., 2014, 16, 516; d) K. Sordakis, C. Tang, L. K. Vogt, H. Junge, P. J. Dyson, M. Beller, G. Laurenczy, Chem. Rev., 2018, 118, 372; d) R. Matheu, M. Z. Ertem, C. Gimbert-Suriñach, X. Sala and A. Llobet, Chem. Rev., 2019, 119, 3453.

${ }^{9}$ V. Courtois, R. Barhdadi, S. Condon and M. Troupel, Tetrahedron Lett., 1999, 40, 5993.

${ }^{10}$ K.-C. Cheung, P. Guo, M.-H. So, L. Y. S. Lee, K.-P. Ho, W.-L. Wong, K.-H. Lee, W.-T. Wong, Z.-Y. Zhou and K.-Y. Wong, J. Organomet. Chem., 2009, 694, 2842

${ }^{11}$ F. Franco, C. Cometto, F. Sordello, C. Minero, L. Nencini, J. Fiedler, R. Gobetto and C. Nervi, ChemElectroChem, 2015, 2, 1372
} 
12 B. Feng, 2008, 350, 2077. Y. Hu, Y. Yu, Z. Hou, H. Li, X. Zhao and B. Feng, Adv. Synth. Catal., 2008, 350, 2077.

${ }^{13}$ C. Romain, S. Gaillard, M. K. Elmkaddem, L. Toupet, C. Fischmeister, C. M. Thomas and J.-L. Renaud, Organometallics, 2010, 29, 1992.

${ }^{14}$ P. Kumar, A. K. Singh, R. Pandey, P.-Z. Li, S. K. Singh, Q. Xu and D. S. Pandey, J. Organomet. Chem., 2010, $695,2205$.

15 P. Haquette, B. Dumat, B. Talbi, S. Arbabi, J.-L. Renaud, G. Jaouen and M. Salmain, J. Organomet. Chem., 2009, $694,937$.

16 P. Haquette, B. Talni, L. Barilleai, N. Madern, C. Fosse and M. Salmain, Org. Biomol. Chem., 2011, 9, 5720.

${ }_{17}^{17}$ A. Chevalley, M. V. Cherrier, J. C. Fontecilla-Camps, M. Ghasemi and M. Salmain, Dalton Trans., 2014, 43, 5482.

${ }^{18}$ S. Wang, V. Dorcet, T. Roisnel, C. Bruneau and C. Fischmeister, Organometallics, 2017, 36, 708

${ }^{19}$ S. Wang, H. Huang, V. Dorcet, T. Roisnel, C. Bruneau and C. Fischmeister, Organometallics, 2017, 36, 3152.

${ }^{20}$ S. Wang, H. Huang, C. Bruneau and C. Fischmeister, ChemSusChem, 2017, 10, 4150.

${ }^{21}$ B. Wozniak, A. Spannenberg, Y. Li, S. Hinze and J. G. de Vries, ChemSusChem, 2018, 11, 356.

22 A. J. B, W. P. Griffith, P. D. Savage, J. Chem. Soc. Dalton Trans. 1995, 3537.

${ }^{23}$ P. Gamez, P. de Hoog, M. Lutz, A. L. Spek and J. Reedijk, Inorg. Chim. Acta, 2003, 351, 319.

${ }^{24}$ N. L. Dias Filho, F. C. M. Portugal, J. M. F. Nogueira, P. Brandão, V. Félix, P. D. Vaz, C. D. Nunes, L. F. Veiros, M. J. V. de Brito and M. J. Calhorda, Organometallics, 2012, 31, 4495.

${ }^{25}$ N. Rahmawati, Y. Ohashi, Y. Honda, M. Kuwahara, K. Fackler, K. Messner and T. Watanabe, Chem. Eng. J., 2005, $112,167$.

${ }^{26}$ K. Bolm, J.-C. Frison, J. L. Paih, C. Moessner and G. Raabe, J. Organomet. Chem., 2004, 689, 3767.

27 B. Feng, Z. Hou, X. Wang, Y. Hu, H. Li and Y. Qiao, Green Chem., 2009, 11, 1446.

${ }^{28}$ A. Bucci, G. Menendez Rodriguez, G. Bellachioma, C. Zuccaccia, A. Poater, L. Cavallo and A. Macchioni, ACS Catal., 2016, 6, 4559.

${ }^{29}$ D. Hong, M. Murakami, Y. Yamada and S. Fukuzumi, Energy Environ. Sci., 2012, 5, 5708.

${ }^{30}$ S. Wang, H. Huang, T. Roisnel, C. Bruneau and C. Fischmeister, ChemSusChem, 2019, 12, 179

31 S. Wang, H. Huang, C. Bruneau and C. Fischmeister, ChemSusChem, 2019, DOI: 10.1002/cssc. 201900626.

32 T. Schareina, G. Hillebrand, H. Fuhrmann and R. Kempe, Eur. J. Inorg. Chem., 2001, 2421.

${ }^{33}$ A. J. Swarts and S. F. Mapolie, Dalton Trans., 2014, 43, 9892.

${ }^{34}$ A. J. Swarts, F. Zheng, V. J. Smith, E. Nordlander and S. F. Mapolie, Organometallics, 2014, 33, 2247.

${ }^{35}$ S. Licciulli, I. Thapa, K. Albahily, I. Korobkov, S. Gambarotta, R. Duchateau, R. Chevalier and K. Schuhen, Angew. Chem. Int. Ed., 2010, 49, 9225.

${ }^{36}$ J. Pan, L. Zhang, L. Bai, Z. Zhang, H. Chen, Z. Cheng and X. Zhu, Polym. Chem., 2013, 4, 2876; L. Bai, L. Zhang, J. Pan, J. Zhu, Z. Chen and X. Zhu, Macromolecules, 2013, 46, 2060.

${ }^{37}$ R. Kröll, C. Eschbaumer, U. S. Schubert, M. R. Buchmeiser and K. Wurst, Macromol. Chem. Phys., 2001, 202, 645.

${ }^{38}$ M. P. Suh, Y.-H. Oh and C.-H. Kwak, Organometallics, 1987, 6, 411.

39 a) A. Furlani, C. Napoletano and M. V. Russo, J. Polym. Sci.: part A: Polym. Chem., 1989, 27, 75; b) A. Furlani, R. Paolesse, M.

V. Russo, A. Camus and N. Marsich, Polymer, 1987, 28, 1221.

40 J. Chin and V. Jubian, J. Chem. Soc., Chem. Commun., 1989, 839.

41 J. Chin, V.Jubian and K. Mrejen, J. Chem. Soc., Chem. Commun., 1990, 1326.

42 R. W. Hay and C. You-Quan, Polyhedron, 1995, 14, 869.

43 R. W. Hay, N. Govan, K. E. Parchment, E. Kiss and T. Clifford, Inorg. React. Mechanisms, 1998, 1, 33.

${ }^{44}$ A. E. Fernandes, A. Dirani, C. d'Haese, G. Deumer, W. Guo, P. Hensenne, F. Nahra, X. Laloyaux, V. Haufroid, B. Nysten, O. Riant and A. M. Jonas, Chem. Eur. J. 2012, 18, 16226.

${ }^{45}$ Y. M. Lee, S. J. Hong, H. J. Kim, S. H. Lee, H. Kwak, C. Kim, S.-J. Kim and Y. Kim, Inorg. Chem. Commun., 2007, 10, 287.

${ }^{46}$ H. Kwak, S. H. Lee, S. H. Kim, Y. M. Lee, E. Y. Lee, B. K. Park, E. Y. Kim, C. Kim, S.-J. Kim and Y. Kim, Eur. J. Inorg. Chem., 2008, 408.

${ }^{47}$ B. K. Park, G. H. Eom, S. H. Kim, H. Kwak, S. M. Yoo, Y. J. Lee, C. Kim, S.-J. Kim and Y. Kim, Polyhedron, 2010, $29,773$.

48 J. H. Lee, H. M. Park, S. P. Jang, G. H. Eom, J. M. Bae, C. Kim, Y. Kim and S.-J. Kim, Inorg. Chem. Commun., 2012, 15, 212.

${ }^{49}$ H. Azoui, K. Baczko, S. Cassel and C. Larpent, Green Chem., 2008, 10, 1197.

50 H. Zhong, J. Wang, L. Li and R. Wang, Dalton Trans., 2014, 43, 2098.

${ }^{51}$ L. Li, T. Wu, J. Wang and R. Wang, ChemPlusChem, 2014, 79, 257.

52 R. Bandari, A. Prager, T. Höche and M. R. Buchmeiser, Arkivoc, 2011, iv, 54.

53 V. Courtois, R. Barhdadi, S. Condon and M. Troupel, Tetrahedron Lett., 1999, 40, 5993.

${ }^{54}$ A. Camus, M. S. Garozzo, N. Marsich and M. Mari, J. Mol. Catal. A: Chem., 1996, 112, 353.

55 Y. Liu, Q.-H. Pang, X.-G. Meng, F.-R. Liu, J.-M. Li, J. Du and C.-W. Hu, J. Appl. Polym. Sci., 2010, 118, 2043.

${ }^{56}$ X.-H. Li, X.-G. Meng, Q.-H. Pang, S.-D. Liu, J.-M. Li, J. Du and C.-W. Hu, J. Mol. Catal. A: Chem., 2010, 328, 88.

${ }^{57}$ E. Sauvageot, R. Marion, F. Sguerra, A. Grimault, R. Daniellou, M. Hamel, S. Gaillard and J.-L. Renaud, Org. Chem. Front., 2014, 1, 639.

58 J. F. Knifton, J. Mol. Catal., 1988, 47, 99.

${ }^{59}$ L. Alvila, T. A. Pakkanen and O. Krause, J. Mol. Catal., 1993, 84, 145.

${ }^{60}$ R. Lescouëzec, G. Marinescu, M. C. Muñoz, D. Luneau, M. Andruh, F. Lloret, J. Faus, M. Julve, J. A. Mata, R. Lusar and J. Cano, New J. Chem., 2001, 25, 1224.

61 M.-C. Suen, Y.-Y. Wu, J.-D. Chen, T.-C. Keng and J.-C. Wang, Inorg. Chim. Acta, 1999, 288, 82-89.

62 S. G. Baca, I. L. Malaestean, T. D. Keene, H. Adams, M. D. Ward, J. Hauser, A. Meels and S. Decurtins, Inorg. Chem., 2008, 47, 11108-11119.

63 F. Zobi, A. Dagonda, M. C. Schaub and A. Y. Bogdanova, Inorg. Chem., 2010, 49, 7313-7322. 
${ }^{64}$ a) A; W. Addison, S. Burman, C. G. Wahlgren, O. A. Rajan, T. M. Rowe and E. Sinn, J. Chem. Soc., Dalton Trans., 1987, 26212630.

65 a) D. E. Morris, Y. Ohsawa, D. P. Segers, M. K. DeArmond and K. W. Hanck, Inorg. Chem., 1984, 23, 3010-3017. b) T. Fukuchi, N. Nagao, E. Miki, K. Mizumachi and T. Ishimori, Bull. Chem. Soc. Jpn, 1989, 62, 2076-2077. c) G. Gupta, S. Gloria, B. Das and K. M. Rao, J. Mol. Struct., 2010, 979, 205-213.

66 J. M. Gichumbi, B. Omondi and H. B. Friedrich, Eur. J. Inorg. Chem., 2017, 915-924.

67 a) F. A. Cotton, L. M. Daniels, G. T. Jordan IV and A. Murillo, Polyhedron, 1998, 17, 589-597. b) F. A. Cotton, L. M. Daniels, G. T. Jordan IV and C. A. Murillo, Chem. Commun., 1997, 1673-1674

68 M. C. Tseng, W. L. Su, Y. C. Yu, S. P. Wang and W. L. Huang, Inorg. Chim. Acta, 2006, 359, 4144-4148.

69 a) H; Hadadzadeh, G. Mansouri, A. Rezvani, H. R. Khavasi, B. W. Skelton, M. Makha and F. R. Charati, Polyhedron, 2011, 30, 2535-2543. b) V. V. Avdeeva, I. N. Polyakova, L. V. Goeva, E. A. Malinina and N. T. Kuznetsov, Russian J. Inorg. Chem., 2016, 61, 302-313.

70 a) M. J. Rauterkus, S. Fakih, C. Mock, I. Puscasu and B. Krebs, Inorg. Chim. Acta, 2003, 350, 355-365. b) M. D. Živković, S. Rajković, U. Rychlewska, B. Warżajtis and M. I. Djuran, Polyhedron, 2007, 26, 1541-1549.

${ }^{71}$ Q. Wang, P. V. Gushchin, N. A. Bokach, M. Haukka and V. Y. Kukushkin, Russian Chem. Bull, Int. Ed., 2012, 61, 828-835.

72 For an example of copper(II) halide complex, see: a) N. Ray, S. Tyagi and B. Hathaway, J. Chem. Soc., Dalton, 1982, $143-146$.

For an example of copper(II) anionic dpa ligand, see: b) O. R. Rodig, T. Brueckner, B. K. Hurlburt, R. K. Schlater, T. L. Venable and E. Sinn, J. Chem. Soc., Dalton, 1981, 1196-199. For an example of neutral copper(I) complex, see: c) N. Marsich, A. Camus, F. Ugozzoli, A. M. Manotti Lanfredi, Inorg. Chim. Acta, 1995, 236, 117-124.

For an example of cationic copper(I) complex, see: J. J. Allen and A. R. Barron, Dalton Trans., 2009, 878-890.

${ }_{73}$ M. Burgos, O. Crespo, M. C. Gimeno, P. G. Jones and A. Laguna, Eur. J. Inorg. Chem., 2003, 2170-2174.

${ }^{74}$ A. Casini, M. C. Diawara, R. Scopelliti, S. M. Zakeeruddin, M. Grätzel and P. J. Dyson, Dalton Trans., 2010, 39, 2239-2245.

75 a) K.-Y. Ho, W.-Y. Yu, K.-K. Cheung and C.-M. Che, Chem. Commun., 1998, 2101-2102; b) Z. Zheng, M. K. Elmkaddem, C. Fischmeister, T. Roisnel, C. M. Thomas, J.-F. Carpentier, J.-L. Renaud, New. J. Chem., 2008, 32, 2150-2158.

${ }^{76} \mathrm{~J}$. Pickardt and B. Staub, Z. Naturforsch., 1999, 54 b, 329-336.

77 a) R. M. K. Deng, K. B. Dillon, A. E. Goeta, M. Mapolelo and H. J. Shepherd, Inorg. Chim. Acta, 2009, 362, 5109-5112. b) J. H. Lee, H. M. Park, S. P. Jang, G. H. Eom, J. M. Bae, C. Kim, Y. Kim and S. J. Kim, Inorg. Chem. Commun., 2012, 15, 212-215.

${ }^{78}$ For chromium photoluminescent complexes, see: a) S. Otto, M. Grabolle, C. Förster, C. Kreitner, U. Resch-Genger and K. Heinze, Angew. Chem. Int. Ed., 2015, 54, 11572-11576. b) S. Otto, N. Scholz, T. Behnke, U. Resch-Genger and K. Heinze, Chem. Eur. J., 2017, 23, 12131-12135. c) S. Otto, C. Förster, C. Wang, U. Resh-Genger and K. Heinze, Chem. Eur. J., 2018, 24, 1255512563.

${ }^{79}$ For photoluminescent rhenium(I) complexes, see: a) M. A. Rohman, D. Sutradhar, S. Sangilipandi, K. M. Rao, A. K. Chandra and S. Mitra, J. Photochem. Photobio. A: Chem., 2017, 341, 115-126. b) N. M. Shavaleev, A. Barbieri, Z. R. Bell, M. D. Ward and F. Barigelletti, New J. Chem., 2004, 28, 398-405.

${ }^{80}$ For photoluminescent ruthenium(II) complexes, see: a) R. L. Blakley and M. K. DeArmond, J. Am. Chem. Soc., 1987, 109, 48954901; b) N. Chanda, S. M. Mobin, V. G. Puranik, A. Datta, M. Niemeyer and G. K. Lahiri, Inorg. Chem., 2004, 43, 1056-1064; c) S. Kar, N. Chanda, S. M. Mobin, A. Datta, F. A. Urbanos, V. G. Puranik, R. Jimenez-Apricio and G. K. Lahiri, Inorg. Chem., 2004, 43, 4911-4920; d) A. Breivogel, C. Förster and K. Heinze, Inorg. Chem., 2010, 49, 7052-7056; e) A. Breivogel, M. Meister, C. Förster, F. Laquai and K. Heinze, Chem. Eur. J., 2013, 19, 13745-13760; f) S. K. Patil, R. Ghosh, P. Kennedy, S. M. Mobin and D. Das, RSC Adv., 2016, 6, 62310-62319; g) C. S. Devi, D. A. Kumar, S. S. Singh, N. Gabra, N. Deepika, Y. P. Kumar and S. Satyanarayana, Eur. J. Med. Chem., 2013, 64, 410-421. h) C. Mari, V. Pierroz, A. Leonidova, S. Ferrari and G. Gasser, Eur. J. Inorg. Chem., 2015, 38793891; i) J.-J. Kim and J. Yoon, Inorg. Chim. Acta, 2013, 394, 506-511.

${ }^{81}$ S.-H. Chang, C.-F. Chang, J.-L. Liao, Y. Chi, D.-Y. Zhou, L.-S. Liao, T.-Y. Jiang, T.-P. Chou, E. Y. Li, G.-H. Lee, T.-Y. Kuo and P.-T. Chou, Inorg. Chem., 2013, 52, 5867-5875.

82 For photoluminescent rhodium(III) complexes, see: W. L. Huang, D. P. Segers and M. K. DeArmong, J. Phys. Chem., 1981, 85, 2080-2086. W. L. Su, Y. C. Yu, M. C. Tseng, S. P. Wang and W. L. Huang, Dalton Trans., 2007, 3440-3449.

${ }^{83}$ For photoluminescent iridium(III) complexes, see: a) W. L. Huang, D. P. Segers and M. K. DeArmong, J. Phys. Chem., 1981, 85, 2080-2086; b) J. R. Lee, Y. R. Liou and W. L. Huang, Inorg. Chim. Acta, 2001, 319, 83-89; c) M. C. Tseng, W. L. Su, Y. C. Yu, S. P. Wang and W. L. Huang, Inorg. Chim. Acta, 2006, 359, 4144-4148; d) T. Hajra, J. K. Bera and V. Chandrasekhar, Inorg. Chim. Acta, 2011, 372, 53-61; e) W.-T. Chen, Y.-J. Chen, C.-S. Wu, J.-J. Lin, W.-L. Su, S.-H. Chen and S.-P. Wang, Inorg. Chim. Acta, 2013, 408, 225-229; f) M. Vaquero, A. Ruiz-Riaguas, M. Martínez-Alonso, F. A. Jalón, B. R. Manzano, A. M. Rodríguez, G. García-Herbosa, A. Carbayo, B. García and G. Espino, Chem. Eur. J., 2018, 24, 10662-10671.

${ }^{84}$ For photoluminescent palladium(II) complexes, see: E. Guney, V. T. Yilmaz and O. Buyugungor, Inorg. Chim. Acta, 2010, 363, 2416-2424.

${ }^{85}$ For photoluminescent platinum(II) complexes, see: a) S. N. Natoli, L. M. Hight, M. Zeller and D. R. McMillin, Inorg. Chem., 2018, 57, 6521-6529; b) S. Wilde, D. González-Abradelo, C.-G. Daniliuc, M. Böckmann, N. Doltsinis and C. A Strassert, Isr. J. Chem., 2018, 58, 932-943; c) S. Wilde, L. Stegemann, C.-G. Daniliuc, T. Koch, N. Doltsinis and C. A Strassert, Z. Naturforsch., 2018, 73, 849-863; d) S. Son, H. Lee, C. Kwak, J. Lee, H. Ahn and M. Chung, J. Nanosci. Nanotechnol., 2015, 15, 5338-5341. I. I. Eliseev, P. V. Gushchin, Y.-A. Chen, P.-T. Chou, M. Haukka, G. L. Starova and V. Y. Kukushkin, Eur. J. Inorg. Chem., 2014, 41014108; e) W. Wu, D. Huang, X. Yi and J. Zhao, Dyes and Pigments, 2013, 96, 220-231; f) D. A. K. Vezzu, J. C. Deaton, J. S. Jones, L. Bartolotti, C. F. Harris, A. P. Marchetti, M. Kondakova, R. D. Pike and S. Huo, Inorg. Chem., 2010, 49, 5107-5119; g) D. Ravindranathan, D. A. K. Vezzu, L. Bartolotti, P. D. Boyle and S. Huo, Inorg. Chem., 2010, 49, 8922-8928; h) D.-R. Bai and S. Wang, 
Organometallics, 2006, 25, 1517-1524; i) Q.-D. Liu, W.-L. Jia, G. Wu and S. Wang, Organometallics, 2003, 22, 3781-3791; j) C. Seward, J. Pang and S. Wang, Eur. J. Inorg. Chem., 2002, 1390-1399.

${ }^{86}$ For photoluminescent copper(I) complexes, see: a) R. Marion, F. Sguerra, F. Di Meo, E. Sauvageot, J.-F. Lohier, R. Daniellou, J.-L. Renaud, M. Linares, M. Hamel and S. Gaillard, Inorg. Chem., 2014, 53, 9181-9191; b) R. Marion, F. Sguerra, F. Di Meo, E. Sauvageot, J.-F. Lohier, R. Daniellou, J.-L. Renaud, M. Linares, M. Hamel and S. Gaillard, Inorg. Chem., 2016, 55, 4068-4068; c) Y. Chen, J.-S. Chen, X. Gan and W.-F. Fu, Inorg. Chim. Acta, 2009, 362, 2492-2498; d) F. Wu, H. Tong, K. Wang, Z. Wang, Z. Li, X. Zhu, W.-Y. Wong and W.-K. Wong, J. Photochem. Photobio. A: Chem., 2016, 318, 97-103.

${ }^{87}$ For photoluminescent silver(I) complexes, see: a) C. Seward, J. Chan, D. Song and S. Wang, Inorg. Chem., 2003, 42, 11121120; b) Y. Kang, C. Seward, D. Song and S. Wang, Inorg. Chem., 2003, 42, 2789-2797.

88 For photoluminescent zinc(II) complexes, see: a) W. Yang, H. Schmider, Q. Wu, Y.-S. Zhang and S. Wang, Inorg. Chem., 2000, 39, 2397-2404. b) C. Yuan, S. N. Liu and X. J. Xu, J. Struct. Chem., 2018, 59, 1922-1927; c) F. Lehchili, F. Setifi, X. Liu, A. Saneei, M. Kučeráková, Z. Setifi, M. Dušek, M. Poupon, M. Pourayoubi and J. Reedijk, Polyhedron, 2017, 131, 27-33; d) E. Molenbroek, N. Straathof, S. Dück, Z. Rashid, J. H. van Lenthe, M. Lutz, A. Grandubert, R. J; M. Klein Gebbink, L. de Cola and S. Bonnet, Dalton Trans., 2013, 42, 2973-2984; e) R. Tan, Z.-B. Wang, Y. Li, D. J. Kozera, Z.-H. Lu, D. Song, Inorg. Chem., 2012, 51, 7039-7049. f) W.-L. Jia, D. Song, S. Wang, J. Org. Chem., 2003, 68, 701-705. g) Y. Kang, C. Seward, D. Song and S. Wang, Inorg. Chem., 2003, 42, 2789-2797; h) C. Seward, J. Pang and S. Wang, Eur. J. Inorg. Chem., 2002, 1390-1399; i) J. Pang, E. J.-P. Marcotte, C. Seward, R. S. Brown and S. Wang, Angew. Chem. Int. Ed., 2001, 40, 4042-4045; j) W. Yang, H. Schmider, Q. Wu, Y.-S. Zhang and S. Wang, Inorg Chem., 2000, 39, 2397-2404; k) K.-Y. Ho, W.-Y. Yu, K.-K. Cheung and C.-M. Che, J. Chem. Soc., Dalton Trans., 1999, 15811586; I) K.-Y. Ho, W.-Y. Yu, K.-K. Cheung and C.-M. Che, Chem. Commun., 1998, 2101-2102.

${ }^{89}$ For photoluminescent cadmium(II) complexes, see: a) F. Lehchili, F. Setifi, X. Liu, A. Saneei, M. Kučeráková, Z. Setifi, M. Dušek, M. Poupon, M. Pourayoubi and J. Reedijk, Polyhedron, 2017, 131, 27-33; b) S. Das, K. Bhar, S. Chantrapromma, H.-K. Fun, R. K. Kanaparthi, A. Samanta and B. K. Ghosh, Inorg. Chim. Acta, 2011, 367, 199-206; c) B. K. Park, G. H. Eom, S. H. Kim, H. Kwak, S. M. Yoo, Y. J. Lee, C. Kim, S.-J. Kim and Y. Kim, Polyhedron, 2010, 29, 773-786.

${ }^{90}$ For photoluminescent mercury(II) complexes, see: a) S. Das, K. Bhar, S. Chantrapromma, H.-K. Fun, R. K. Kanaparthi, A. Samanta and B. K. Ghosh, Inorg. Chim. Acta, 2011, 367, 199-206; b) J. H. Lee, H. M. Park, S. P. Jang, G. H. Eom, J. M. Bae, C. Kim, Y. Kim and S.J. Kim, Inorg. Chem. Commun., 2012, 15, 212-215.

${ }_{91}$ T. Tsujimura, OLED Display Fundamentals and Applications, $2^{\text {nd }}$ Ed., John Wiley \& Sons, Hoboken, 2017.

92 R. D. Costa, Light-Emitting Electrochemical Cells, Springer International AG, 2017.

93 a) G. H. V. Bertrand, M. Hamel, S. Normand and F. Sguerra, Nucl. Inst. Meth. Phys. Res. A, 2015, 776, 114-128; b) G. H. V. Bertrand, M. Hamel and F. Sguerra, Chem. Eur. J., 2014, 20, 15660-15685.

${ }^{94}$ a) W.L. Jia, Q.-D. Liu, D. Song and S. Wang, Organometallics, 2003, 22, 321-327. b) J. Lee, Q.-D., M. Motala, J. Dane, J. Gao, Y. Kang and S. Wang, Chem. Mater., 2004, 16, 1869-1877.

95 W.-L. Jia, R.-Y. Wang, D. Song, S. J. Ball, A. B. McLean and S. Wang, Chem. Eur. J., 2005, 11, 832-842.

${ }^{96}$ J. Ni, K.-J. Wei, Y. Min, Y. Chen, S. Zhan, D. Li and Y. Liu, Dalton Trans., 2012, 41, 5280-5293.

97 B. Antionioti, D. J. Bray, J. K. Clegg, K. Gloe, K. Gloe, O. Kataeva, L. F. Lindoy, J. C. McMurtrie, P. J. Steel, C. J. Sumby and M. Wenzel, Dalton Trans, 2006, 4783-4794.

98 W. Yang, H. Schmider, Q. Wu, Y.-S. Zhang and S. Wang, Inorg Chem., 2000, 39, 2397-2404.

${ }_{99}$ C. Seward, J. Chan, D. Song and S. Wang, Inorg. Chem., 2003, 42, 1112-1120.

100 S. Martíc, G. Wu and S. Wang, Inorg. Chem., 2008, 47, 8315-8323.

101 D. A. K. Vezzu, J. C. Deaton, J. S. Jones, L. Bartolotti, C. F. Harris, A. P. Marchetti, M. Kondakova, R. D. Pike and S. Huo, Inorg. Chem., 2010, 49, 5107-5119.

102 X.-Q. Zhang, Y.-M. Xie, Y. Zheng, F. Liang, B. Wang, J. Fan and L.-S. Liao, Organic Electronics, 2016, 32, 120-125.

103 S.-H. Chang, C.-F. Chang, J.-L. Liao, Y. Chi, D.-Y. Zhou, L.-S. Liao, T.-Y. Jiang, T.-P. Chou, E. Y. Li, G.-H. Lee, T.-Y. Kuo and P.-T. Chou, Inorg. Chem., 2013, 52, 5867-5875

104 a) S. Otto, M. Grabolle, C. Förster, C. Kreitner, U. Resch-Genger and K. Heinze, Angew. Chem. Int. Ed., 2015, 54, 11572-11576. b) S. Otto, N. Scholz, T. behnke, U. Resch-Genger and K. Heinze, Chem. Eur. J., 2017, 23, 12131-12135.

${ }^{105}$ A. Breivogel, M. Park, D. Lee, S. Klassen, A. Kühnle, C. Lee, K. Char and K. Heinze, Eur. J. Inorg. Chem., 2014, 288-295.

${ }^{106}$ V. A. Krylova, P. I. Djurovich, M. T. Whited and M. E. Thompson, Chem. Commun., 2010, 46, 6696-6698.

107 M. Elie, M. D. Weber, F. Di Meo, F. Sguerra, J.-F. Lohier, R. B. Pansu, J.-L. Renaud, M. Hamel, M. Linares, R. D. Costa and S. Gaillard, Chem. Eur. J., 2017, 23, 16328-16337.

108 M. Elie, F. Sguerra, F. Di Meo, M. D. Weber, R. Marion, A. Grimault, J.-F. Lohier, A. Stallivieri, A. Broseau, R. B. Pansu, J.-L. Renaud, M. Linares, M. Hamel, R. D. Costa and S. Gaillard, ACS Appl. Mater. \& Inter., 2016, 8, 14678-14691.

109 a) G. H. V. Bertrand, M. Hamel, S. Normand and F. Sguerra, Nucl. Inst. Meth. Phys. Res. A, 2015, 776, 114-128. b) G. H. V. Bertrand, M. Hamel and F. Sguerra, Chem. Eur. J., 2014, 20, 15660-15685.

110 F. Sguerra, R. Marion, G. H. V. Bertrand, R. Coulon, E. Sauvageot, R. Daniellou, J.-L. Renaud, S. Gaillard and M. Hamel, J. Mater. Chem. C, 2014, 2, 6125-6133.

111 Z. Jin, H. Masuda, N. Yamanaka, M. Minami, T. Nakamura and Y. Nishikitani, Chem. Lett., 2009, 38, 44-45.

112 a) M. Grätzel, Acc. Chem. Res., 42, 1788-1798. I. b) Chung, B. Lee, J. He, R. P. H. Chang and M. G. Kanatzidis, Nature, 485, 2012, 486-489.

113 J.-J. Kim and J. Yoon, Inorg. Chim. Acta, 2013, 394, 506-511.

${ }^{114}$ A. Breivogel, S. Wooh, J. Dietric, T. Y. Kim, Y. S. Kang, K. Char and K. Heinze, Eur. J. Inorg. Chem., 2014, $2720-2734$.

115 A. K. C. Mengel, W. Cho, A. Breivogel, K. Char, Y. S. Kang and K. Heinze, Eur. J. Inorg. Chem., 2015, 3299-3306.

${ }^{116}$ C. Kreitner, A. K. C. Mengel, T. K. Lee, W. Cho, K. Char, Y. S. Kang and K. Heinze, Chem. Eur. J., 2016, 22, 8915-8928. 